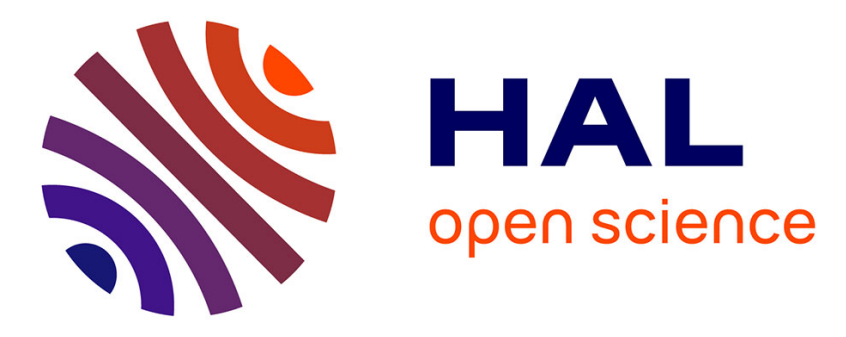

\title{
Structural and tidal models of Titan and inferences on cryovolcanism
}

\author{
F. Sohl, A. Solomonidou, F. Wagner, A. Coustenis, H. Hussmann, D. \\ Schulze-Makuch
}

\section{- To cite this version:}

F. Sohl, A. Solomonidou, F. Wagner, A. Coustenis, H. Hussmann, et al.. Structural and tidal models of Titan and inferences on cryovolcanism. Journal of Geophysical Research. Planets, 2014, 119 (5), pp.1013-1036. 10.1002/2013JE004512 . hal-02541885

\section{HAL Id: hal-02541885 \\ https://hal.science/hal-02541885}

Submitted on 31 Dec 2021

HAL is a multi-disciplinary open access archive for the deposit and dissemination of scientific research documents, whether they are published or not. The documents may come from teaching and research institutions in France or abroad, or from public or private research centers.
L'archive ouverte pluridisciplinaire HAL, est destinée au dépôt et à la diffusion de documents scientifiques de niveau recherche, publiés ou non, émanant des établissements d'enseignement et de recherche français ou étrangers, des laboratoires publics ou privés. 


\section{Journal of Geophysical Research: Planets}

\section{RESEARCH ARTICLE \\ 10.1002/2013JE004512 \\ Structural and tidal models of Titan and inferences on cryovolcanism}

Key Points:

- Interior models and amplitude patterns of diurnal tidal stresses are calculated

- The diurnal tidal stress pattern is compliant with cryovolcanic candidate areas

- A warm, low-ammonia ocean could increase Titan's habitable potential

Correspondence to:

F. Sohl,

frank.sohl@dlr.de

\section{Citation:}

Sohl, F., A. Solomonidou, F. W. Wagner, A. Coustenis, H. Hussmann, and D. Schulze-Makuch (2014), Structural and tidal models of Titan and inferences on cryovolcanism, J. Geophys. Res. Planets, 119, 1013-1036, doi:10.1002/2013JE004512.

Received 30 AUG 2013 Accepted 16 APR 2014 Accepted article online 23 APR 2014 Published online 12 MAY 2014

\author{
F. Sohl ${ }^{1}$, A. Solomonidou ${ }^{2,3,4}$, F. W. Wagner ${ }^{1,5}$, A. Coustenis ${ }^{2}$, H. Hussmann ${ }^{1}$, and D. Schulze-Makuch ${ }^{6,7}$ \\ ${ }^{1}$ DLR, Institute of Planetary Research, Berlin, Germany, ${ }^{2}$ LESIA, Observatoire de Paris, CNRS, UPMC University Paris 06, \\ University Paris-Diderot-Meudon, Paris, France, ${ }^{3}$ Department of Geology and Geoenvironment, National and Kapodistrian \\ University of Athens, Athens, Greece, ${ }^{4}$ Now at Jet Propulsion Laboratory, California Institute of Technology, Pasadena, \\ California, USA, ${ }^{5}$ Westphalian Wilhelms-University, Institute for Planetology, Münster, Germany, ${ }^{6}$ School of Earth and \\ Environmental Sciences, Washington State University, Pullman, Washington, USA, ${ }^{7}$ Center for Astronomy and \\ Astrophysics, Technical University of Berlin, Berlin, Germany
}

Abstract Titan, Saturn's largest satellite, is subject to solid body tides exerted by Saturn on the timescale of its orbital period. The tide-induced internal redistribution of mass results in tidal stress variations, which could play a major role for Titan's geologic surface record. We construct models of Titan's interior that are consistent with the satellite's mean density, polar moment-of-inertia factor, obliquity, and tidal potential Love number $k_{2}$ as derived from Cassini observations of Titan's low-degree gravity field and rotational state. In the presence of a global liquid reservoir, the tidal gravity field is found to be consistent with a subsurface water-ammonia ocean more than $180 \mathrm{~km}$ thick and overlain by an outer ice shell of less than $110 \mathrm{~km}$ thickness. The model calculations suggest comparatively low ocean ammonia contents of less than $5 \mathrm{wt}$ $\%$ and ocean temperatures in excess of $255 \mathrm{~K}$, i.e., higher than previously thought, thereby substantially increasing Titan's potential for habitable locations. The calculated diurnal tidal stresses at Titan's surface amount to $20 \mathrm{kPa}$, almost comparable to those expected at Enceladus and Europa. Tidal shear stresses are concentrated in the polar areas, while tensile stresses predominate in the near-equatorial, midlatitude areas of the sub- and anti-Saturnian hemispheres. The characteristic pattern of maximum diurnal tidal stresses is largely compliant with the distribution of active regions such as cryovolcanic candidate areas. The latter could be important for Titan's habitability since those may provide possible pathways for liquid water-ammonia outbursts on the surface and the release of methane in the satellite's atmosphere.

\section{Introduction}

Titan, Saturn's largest satellite, is the only satellite with a substantial atmosphere mainly composed of nitrogen and is in several aspects quite similar to our own planet (in terms of atmospheric composition, surface pressure, and organic chemistry in particular) in spite of the satellite's ice-rich bulk composition. Titan is tidally locked with respect to Saturn and subject to periodic tidal forcing of its interior and surface, resulting in diurnal stresses at the satellite's surface. In addition, with one hundred Titan flybys to date, the Cassini-Huygens mission exploring the Saturnian system since 2004 has revealed the remarkable geologic diversity of Titan's surface, exhibiting a number of features morphologically similar to what is found on our own planet [e.g., Jaumann et al., 2009; Coustenis and Hirtzig, 2009; Solomonidou et al., 2013], albeit composed of different materials (ice instead of rock, hydrocarbons in different phases instead of water). The geologic surface features are partly attributed to exchange processes between the satellite's interior, its surface, and its atmosphere [Grasset et al., 2010].

From the Cassini spacecraft, Titan's landscape has been observed by multiple flybys, examining the surface expressions through radar and infrared instrumentation. The images obtained using the Cassini Synthetic Aperture Radar instrument and the Imaging Science Subsystem (ISS) revealed that Titan hosts a complex surface characterized by mountains, drainage networks, dunes, faults, and possibly volcanic-like features [Jaumann et al., 2008; Lopes et al., 2010, 2013; Solomonidou et al., 2013, and references therein], which resemble Earth-like geologic structures and terrains [e.g., Coustenis and Hirtzig, 2009]. Only a few impact craters have been identified on Titan owing to intense resurfacing [Wood et al., 2010]. Furthermore, the visual and infrared mapping spectrometer (VIMS) on board the Cassini spacecraft provides spectral imaging of Titan's surface at specific wavelengths in the 0.8 to $5.2 \mu \mathrm{m}$ range. These are indicative of the diversity of the geologic terrain types, which are subject to complex erosional and depositional processes. The 
surface properties can be inferred from such observations using narrow methane spectral " windows" located in the near-infrared and centered at $0.93,1.08,1.27,1.59,2.03,2.79$, and $5.00 \mu \mathrm{m}$, where the methane absorption is weak enough to allow for probing of the surface [McKay et al., 1989; Griffith et al., 1991]. When atmospheric scattering and absorption effects are properly accounted for, information on the nature of the surface can be extracted using radiative transfer codes [e.g., Hirtzig et al., 2013].

The nonspherical part of Titan's static gravitational field is predominated by spin and tidal contributions. Using different flyby geometries of the Cassini spacecraft, less et al. [2010] determined the polar oblateness and equatorial ellipticity of the static gravity field independently from each other. Titan's ratio of the corresponding tidal and spin gravity coefficients $C_{2,2}$ and $J_{2}$ is close to the theoretical prediction of $3 / 10$ for a synchronously rotating satellite in hydrostatic equilibrium, from which less et al. [2010] infer an upper bound of 0.34 for Titan's axial moment-of-inertia (Mol) factor. If nonhydrostatic contributions are tentatively attributed to the degree-3 terms, Titan's Mol factor may be as low as 0.33 [see less et al., 2010] (supporting information), which is still inconsistent with fully differentiated interior models of Titan that would produce even smaller Mol factors [e.g., Grasset et al., 2000; Sohl et al., 2003; Tobie et al., 2005]. Nimmo and Bills [2010] explain Titan's shape or long-wavelength topography [Zebker et al., 2009] and the small magnitude of associated gravity anomalies [less et al., 2010] in terms of lateral thickness variations of a conductive floating outer ice shell with isostatically compensated ice topography and about $100 \mathrm{~km}$ thick on average.

Titan's significant orbital eccentricity and obliquity cause periodic variations of the nonspherical part of the static gravitational field resulting in diurnal stresses at the satellite's surface. These diurnal tides could play a major role for Titan's geologic surface record. For example, the formation of cycloidal features and strike-slip faults on synchronous satellites such as Europa is attributed to diurnal tidal stresses induced by nonzero orbital eccentricity, nonzero spin-axis obliquity, and physical librations of their outer shell being mechanically decoupled from the deep interior [Hurford et al., 2009; Jara-Orué and Vermeersen, 2011]. A measure for the tide-induced internal redistribution of mass is the degree- 2 body tide Love number $k_{2}$ that is related to the radial density distribution and rheological structure of Titan. Radio science data from six close flybys of the Cassini spacecraft allowed less et al. [2012] to infer two solutions for $k_{2}$ of $0.589 \pm 0.15$ and $0.637 \pm 0.224$ (both with $2 \sigma$ errors), respectively, corresponding to tidal variations of about $4 \%$ relative to the static degree-2 terms, which is consistent with the existence of a global ocean at depth. Baland et al. [2011] and Bills and Nimmo [2011] invoke the presence of an outer ice shell, mechanically decoupled from the deep interior by a subsurface ocean, as plausible explanation for Titan's notable spin axis obliquity of about $0.3^{\circ}$ relative to the orbit pole [Stiles et al., 2008, 2010].

In the present study, we focus on the distribution of diurnal tidal stresses at the satellite's surface and possible links to geologic surface features on Titan. In section 2, we describe the construction of structural models of Titan's interior based on Cassini gravity data and how the corresponding tidal stress pattern at Titan's surface is calculated. Results are presented in section 3 and put into perspective with morphotectonic surface features and related geologic processes in section 4. Finally, section 5 discusses possible connections between the diurnal tidal stress pattern and volcanic-like and tectonic-like surface features on Titan with implications for the satellite's habitable potential.

\section{Model Description}

Structural models of Titan's interior are required to satisfy the global parameters that are listed in Table 1. In the absence of seismological observations, gravitational field and rotational data provide important information on the satellite's radial mass distribution and rheological structure. The gravitational field and rotational data collected by the Cassini mission suggest that Titan is in almost perfect hydrostatic equilibrium with its tidal and centrifugal potential. Furthermore, the orientation of Titan's spin pole is consistent with the assumption that the satellite's outer ice shell is partly decoupled from the deep interior by a subsurface ocean (see Appendix A).

less et al. [2010] concluded that the Cassini gravitational field observations could be explained either by incomplete separation of the primordial ice-rock mixture or the presence of a substantially hydrated silicate core. However, the former hypothesis has been challenged by parameterized thermal evolution models, suggesting that Titan's rock content were sufficiently high to facilitate substantial melting and complete separation of the primordial ice-rock mixture [O'Rourke and Stevenson, 2014], whereas the latter requires 
Table 1. Global Parameters of Titan

\begin{tabular}{lcccc} 
Parameter & Symbol & Units & Value & Uncertainty \\
\hline Mean radius $^{\mathrm{a}}$ & $R_{s}$ & $\mathrm{~km}$ & 2575.5 & \pm 2.0 \\
Total mass $^{\mathrm{a}}$ & $m_{t}$ & $10^{23} \mathrm{~kg}$ & 1.3452728 & \pm 0.0000058 \\
Surface pressure $^{\mathrm{b}}$ & $P_{s}$ & $\mathrm{bar}$ & 1.467 & \pm 0.001 \\
Surface temperature $^{\mathrm{b}}$ & $T_{s}$ & $\mathrm{~K}$ & 93.65 & \pm 0.25 \\
Degree-2 gravity coefficient $^{\mathrm{c}}$ & $J_{2}$ & - & 33.46 & \pm 0.63 \\
Degree-2 gravity coefficient $^{\mathrm{c}}$ & $\mathrm{C}_{2,2}$ & - & 10.02 & \pm 0.07 \\
Moment-of-inertia factor $^{\mathrm{c}}$ & $\mathrm{Mol}$ & - & 0.3414 & \pm 0.0005 \\
Degree-2 Love number $^{\mathrm{d}}$ & $k_{2}$ & - & 0.589 & $\pm 0.15(2 \sigma)$ \\
Free orbital eccentricity $^{\mathrm{d}}$ & $e$ & - & 0.028 & - \\
Obliquity $^{\mathrm{e}}$ & $v$ & $\mathrm{deg}$ & -0.32 & \pm 0.02 \\
Orbit inclination $^{\mathrm{f}}$ & $i$ & $\mathrm{deg}$ & 0.28 & - \\
Mean orbital motion $^{\mathrm{g}}$ & $\omega$ & $10^{-6} \mathrm{~s}^{-1}$ & 4.56 & - \\
Orbital period $^{\mathrm{g}}$ & $P_{\mathrm{o}}$ & $\mathrm{day}$ & 15.945 & - \\
Nodal regression period $^{\mathrm{f}}$ & $P_{n}$ & year & 607.56 & - \\
\hline
\end{tabular}

a Sohl et al. [2009, and references therein].

${ }^{\mathrm{b}}$ Fulchignoni et al. [2005].

cless et al. [2010].

d less et al. [2012].

e Baland et al. [2011].

$\mathrm{f}$ Bills and Nimmo [2008].

gSohl et al. [2003, and references therein].

efficient removal of long-lived radiogenic heat sources such as potassium from the core to delay the onset of silicate dehydration [Castillo-Rogez and Lunine, 2010; Fortes, 2012].

In the present study, we consider hydrated silicate cores because fully differentiated interior structure models are difficult to maintain considering Titan's inferred axial moment of inertia [less et al., 2010]. We note that compositional details regarding the long-term stability of hydrated silicates, e.g., the accumulation of sodium and potassium leached early in Titan's history at the ice-rock interface during ocean freezing [Zolotov, 2007; Sohl et al., 2010], are not central to the present study because we are mainly interested in the outer part of Titan's mechanical structure that determines the satellite's tidal response at the surface.

We here assume that Titan is close to hydrostatic equilibrium and that the satellite's present interior structure can be characterized by four chemically homogeneous reservoirs, consisting of a hydrated silicate core (Appendix B), a high-pressure pure water-ice mantle (Appendix C), and a subsurface water-ammonia ocean overlain by a conductive floating outer ice shell composed of low-pressure water-ice lh and sl methane hydrate (Appendix D).

The set of differential equations for mass $m$, moment of inertia $l$, gravitational acceleration $g$, and hydrostatic pressure $P$ can be derived from fundamental principles:

$$
\begin{gathered}
\frac{\mathrm{d} m}{\mathrm{~d} r}=4 \pi r^{2} \rho, \\
\frac{\mathrm{d} l}{\mathrm{~d} r}=\frac{8}{3} \pi r^{4} \rho, \\
\frac{\mathrm{d} g}{\mathrm{~d} r}=4 \pi \mathrm{G} \rho-2 \frac{g}{r}, \\
\frac{\mathrm{d} P}{\mathrm{~d} r}=-g \rho+\frac{2}{3} \omega^{2} r \rho,
\end{gathered}
$$

where $r$ is the radial distance from Titan's center, $G$ is the gravitational constant, $\omega$ is Titan's rotational angular frequency, and $\rho$ is the local density, which will be explained in detail further below.

Throughout the silicate core and the high-pressure water-ice shell, we calculate the thermal structure by solving the following two differential equations for heat flux $q$ and temperature $T$ in thermal steady state:

$$
\frac{\mathrm{d} q}{\mathrm{~d} r}=\epsilon \rho-2 \frac{q}{r}
$$




$$
\frac{\mathrm{d} T}{\mathrm{~d} r}=-\frac{q}{N u_{r} k_{c}}
$$

where $k_{c}$ is the thermal conductivity and $N u_{r}$ is the local Nusselt number. Here the subscript $r$ explicitly indicates that the quantity is a local function of pressure, temperature, and composition. The specific heat production rate $\epsilon$ is adjusted to meet Titan's surface temperature $T_{s}$ of $94 \mathrm{~K}$.

The local Nusselt number parameterizes the strength of the convective heat flux and can be expressed as [Wagner et al., 2011]

$$
N u_{r}=\left(1+\frac{k_{v}}{k_{c}}\right)\left(\frac{q}{q-k_{v} \nabla T_{S}}\right)
$$

where $k_{v}$ is an effective thermal conductivity due to convection [Kimura et al., 2009; Wagner et al., 2012] and $\nabla T_{S}=-g \alpha T / C_{p}$ is the adiabatic temperature gradient, with the thermal expansivity $\alpha$ and the specific heat capacity $C_{p}$. The effective thermal conductivity $k_{v}$ is dependent on viscosity and obtained from the modified mixing length theory developed by Sasaki and Nakazawa [1986] to model low Reynolds number flow in solid planetary bodies. The viscosity of the silicate core is adjusted such that the central temperature will not exceed a critical threshold temperature of about $900 \mathrm{~K}$ for silicate dehydration [e.g., Perrillat et al., 2005; Castillo-Rogez and Lunine, 2010].

The mixing length approach allows to formulate a localized stability criterion for the onset of thermal convection, which is based on the comparison between the local temperature gradient and the adiabatic temperature gradient. If the local temperature gradient is superadiabatic, $k_{v}$ is greater than zero, buoyant material will rise due to the density contrast to the surrounding matter, resulting in a local Nusselt number (equation (7)) larger than unity. If the local temperature gradient is subadiabatic, $k_{v}$ is zero, the fluid material is stably stratified with respect to thermal convection, and the local Nusselt number equals one. Although this treatment slightly overestimates the heat flux at very low Rayleigh numbers [Abe, 1995], the extended mixing length theory has been successfully applied in previous studies [e.g., Sasaki and Nakazawa, 1986; Abe, 1997; Senshu et al., 2002; Kimura et al., 2007, 2009; Tachinami et al., 2011; Wagner et al., 2012].

For the sake of simplicity, the thermal structure of the outer ice shell and the subsurface water-ammonia ocean is imposed by assuming a fixed thermal gradient from the given surface temperature $T_{s}$ of $94 \mathrm{~K}$ to the temperature of the subsurface water-ammonia ocean $T_{o}$ that is taken to be constant. The temperature gradient is given by the ratio between the temperature contrast and the thickness of the ice shell. With that simplified approach, we also ignore the possible existence of a thin convective sublayer at the base of the outer ice shell.

Successful models are required to satisfy Titan's global parameters listed in Table 1 . While the central conditions are $m(0)=0, l(0)=0, g(0)=0, P(0)=P_{c}, q(0)=0$, and $T(0) \leq 900 \mathrm{~K}$, the surface conditions are $m\left(R_{s}\right)=m_{t^{\prime}} l\left(R_{s}\right)=(0.34 \pm 0.005) m_{t} R_{s}^{2}, g\left(R_{s}\right)=G m_{t} / R_{s^{\prime}}^{2} P\left(R_{s}\right)=1.467$ bar, $q\left(R_{s}\right)=q_{s}$, and $T\left(R_{s}\right)=94 \mathrm{~K}$. Furthermore, the radius of the silicate core is derived from mass balance constraints, whereas the radial extent of the subsurface water-ammonia ocean sandwiched between low- and high-pressure ice shells is calculated in accordance with the phase diagram of the $\mathrm{H}_{2} \mathrm{O}-\mathrm{NH}_{3}$ system.

\subsection{Density and Elastic Moduli}

The differential equations described above are dependent on the local density $\rho$, which can be obtained from an equation of state. Apart from the outer ice shell, the density is calculated by using Murnaghan's integrated linear equation of state [Murnaghan, 1967]:

$$
\rho(T, P)=\rho_{0}(T)\left(1+K^{\prime}(T) \frac{P}{K_{0}(T)}\right)^{1 / K^{\prime}},
$$

where $\rho_{0}$ and $K_{0}$ are the density and isothermal bulk modulus at the reference pressure $\left(P=P_{0}=0 \mathrm{~Pa}\right)$, respectively, and $K^{\prime}$ is the first pressure derivative of the isothermal bulk modulus $K$.

The isothermal bulk modulus can be assessed by expanding $K$ to the first order in pressure $P$ :

$$
K(T, P)=K_{0}(T)+K^{\prime} P
$$


$K^{\prime}$ is explicitly dependent on temperature in the water-ammonia ocean and is taken constant in the silicate core, high-pressure ice layer, and outer ice shell. Furthermore, the rigidity $\mu$, the adiabatic bulk modulus $K$, and the density $\rho$ are related to the velocities of the compressional and shear wave $v_{\rho}$ and $v_{S}$, respectively,

$$
\begin{gathered}
v_{P}=\sqrt{\frac{K+(4 / 3) \mu}{\rho},} \\
v_{S}=\sqrt{\frac{\mu}{\rho}},
\end{gathered}
$$

where we assume that the adiabatic and isothermal bulk modulus are approximately equal, i.e., $K_{S} \sim K_{T}=K$, under the relatively low temperature and pressure conditions prevalent in the interior of Titan.

For the hydrated silicate core, we apply the Guinan-Steinberg model to calculate the pressure dependent shear modulus at depth [Guinan and Steinberg, 1975]:

$$
\mu(P)=\mu_{0}+\mu^{\prime} \frac{P}{x^{1 / 3}},
$$

where $\mu_{0}$ and $\mu^{\prime}$ are the shear modulus and its pressure derivative at zero pressure, respectively, and $x$ denotes the compression ratio $\rho / \rho_{0}$. The temperature dependency of the shear modulus has been omitted owing to the relatively low temperatures that must be expected in Titans interior $(T(0) \leq 900 \mathrm{~K})$. The Guinan-Steinberg model is a well-established approach to predict the shear modulus of materials at high pressures. We use the Guinan-Steinberg model in the same way as we use an equation of state (EoS) and fit it to data obtained from high-pressure experiments or first principles calculations to determine the reference parameters for equation (12) as listed in Table B1. Hence, the obtained relationships are only valid to the limited pressure range (up to about $5 \mathrm{GPa}$ ) they have been fitted for and should not be used for extrapolation beyond the fitted range. The seismic velocities $v_{P}$ and $v_{S}$ are then obtained according to equations (10) and (11).

Gagnon et al. [1990] measured sound wave velocities in water-ice VI via Brillouin spectroscopy. They found the following pressure-dependent relationships:

$$
\begin{aligned}
& v_{P}=4.193+0.0456(P / \mathrm{kbar}), \\
& v_{S}=1.987+0.0463(P / \mathrm{kbar}),
\end{aligned}
$$

where $v_{P}$ and $v_{S}$ are compressional and shear wave speed, respectively. We use both equations to calculate the seismic velocities within the high-pressure water-ice layer and obtain the depth-dependent rigidity $\mu$ using equation (11).

Since the shear modulus $\mu$ of a liquid vanishes, equation (10) simplifies to the bulk sound velocity

$$
v_{P}=\sqrt{\frac{K}{\rho}},
$$

which we use to calculate the compressional wave velocity $v_{P}$ within the subsurface water-ammonia ocean.

The outermost ice shell is assumed to be composed of water-ice lh and sl methane hydrate. Using a linear planar fit, Helgerud et al. [2009] report equation of state and elastic parameters that are based on laboratory data:

$$
F(T, P)=A^{*} T+B^{*} P+C^{*},
$$

where $F$ is the desired value (e.g., the local density $\rho$ and elastic moduli $K$ and $\mu$ ).

Modeling details for each structural layer are presented in the Appendices B, C, and D. 


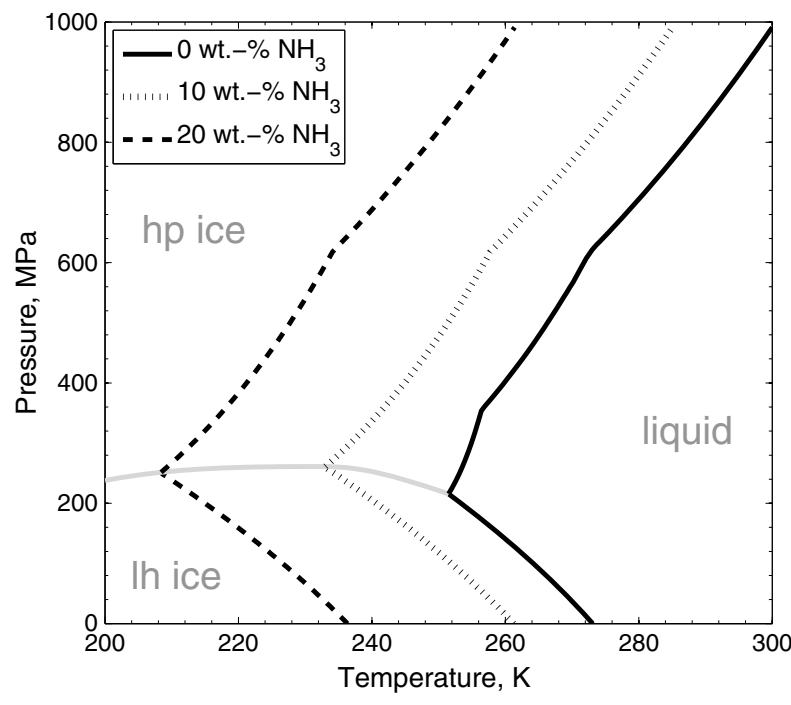

Figure 1. Liquidus curves of the water-ammonia $\left(\mathrm{H}_{2} \mathrm{O}-\mathrm{NH}_{3}\right)$ system for $\mathrm{NH}_{3}$ concentrations of 0,10 , and 20 wt \%. See text for further details.

derived by Leliwa-Kopystyński et al. [2002] as follows:

\subsection{Interfaces}

The interface between nearby chemical reservoirs is determined by the water-ammonia phase diagram and Titan's global parameters as listed in Table 1.

The thickness of the subsurface water-ammonia ocean sandwiched between low- and high-pressure ice shells is calculated in accordance with the phase diagram of the $\mathrm{H}_{2} \mathrm{O}-\mathrm{NH}_{3}$ system shown in Figure 1. As a consequence, the intersections of the calculated local geotherm and the melting conditions for a fixed ocean temperature determine the radial extent of the chemical reservoirs within Titan's water-ice/liquid shell above the silicate core.

For the low-pressure water-ice (Ih), the melting temperature $T_{m}$ as a function of pressure $P_{m}$ and ammonia content $\chi$ was

$$
T_{m}\left(P_{m}, \chi\right)=T_{\text {ref }}-a P_{m}-b P_{m}^{2}-c \chi-d \chi^{2}-e P_{m} \chi
$$

where $T_{\text {ref }}$ is a reference temperature of $273.1 \mathrm{~K}$ and $a, b, c, d$, and $e$ are experimentally determined fit parameters. The corresponding fit parameters for the low-pressure melting curve of a $\mathrm{H}_{2} \mathrm{O}-\mathrm{NH}_{3}$ mixture are $a=7.95 \times 10^{-8} \mathrm{~K} \mathrm{~Pa}^{-1}, b=9.6 \times 10^{-17} \mathrm{~K} \mathrm{~Pa}^{-2}, c=53.8 \mathrm{~K}, d=650 \mathrm{~K}$, and $e=4 \times 10^{-8} \mathrm{~K} \mathrm{~Pa}^{-1}$ [Leliwa-Kopystyński et al., 2002].

When considering the high-pressure phases of water-ice (III, V, and VI), a similar parameterization relating the melting temperature $T_{m}$ to pressure $P_{m}$ and ammonia content $\chi$ is given by [Choukroun and Grasset, 2007, 2010]

$$
T_{m}\left(P_{m}, \chi\right)=T_{\text {ref }}\left(\frac{P_{m}-P_{\text {ref }}}{a}+1\right)^{1 / c}-b \chi^{d},
$$

where $T_{\text {ref }}$ and $P_{\text {ref }}$ are reference values, respectively, and $a, b, c$, and $d$ are fit parameters. The latter term of equation (18) has been obtained from Figure 5 in Choukroun and Grasset [2010]. It roughly quantifies the reduction in melting temperature of the high-pressure water-ice polymorphs when ammonia is added into the water liquid. We list the corresponding values with respect to the appropriate water-ice phases in Table 2.

The interface between the water-ice-dominated mantle and the silicate core is then completely constrained by the global properties of Titan described in the previous section. In other words, the radius of the core is

Table 2. Parameters for the High-Pressure Melting Curve of $\mathrm{H}_{2} \mathrm{O}-\mathrm{NH}_{3}$ Mixtures

\begin{tabular}{cccccc}
$T_{\text {ref }}(\mathrm{K})$ & $P_{\text {ref }}(\mathrm{MPa})$ & $a(\mathrm{MPa})$ & $b^{\mathrm{a}}(\mathrm{K})$ & $c$ & $d^{\mathrm{a}}$ \\
\hline 251.15 & 209.5 & 101.1 & 350 & 42.86 & 1.37 \\
256.43 & 355.0 & 373.6 & 350 & 8.66 & 1.37 \\
272.73 & 618.4 & 661.4 & 350 & 4.69 & 1.37 \\
\hline
\end{tabular}

a Estimated from Figure 5 in Choukroun and Grasset [2010]. References: [Choukroun and Grasset, 2007, 2010]. determined from mass balance constraints and Titan's physical properties as listed in Table 1.

\subsection{Diurnal Tides and Tidal Stresses} Titan is subject to time-varying radial and librational tides exerted by Saturn on the timescale of its orbital period. Disregarding small contributions due to obliquity tides, the main tidal potential is given by 
[Segatz et al., 1988; Moore and Schubert, 2000; Wahr et al., 2009; Jara-Orué and Vermeersen, 2011; Hussmann et al., 2011; Beuthe, 2013]

$$
\begin{aligned}
\Phi_{e}(r, \theta, \phi, t)= & r^{2} \omega^{2} e \\
& \times\left[-\frac{3}{2} P_{2}^{0}(\cos \theta) \cos \omega t+\frac{1}{4} P_{2}^{2}(\cos \theta)(3 \cos \omega t \cos 2 \phi+4 \sin \omega t \sin 2 \phi)\right],
\end{aligned}
$$

where $r$ is the radial distance from the center of Titan and $\omega$ and $e$ are Titan's mean motion and orbital eccentricity, respectively. $P_{2}^{0}(\cos \theta)=1 / 2\left(3 \cos ^{2} \theta-1\right)$ and $P_{2}^{2}(\cos \theta)=3\left(1-\cos ^{2} \theta\right)$ are associated Legendre polynomials of second degree. $\theta$ and $\phi$ are colatitude and longitude with zero longitude at the sub-Saturnian point, and $t$ is time. Owing to the external gravitational perturbation by Saturn the equipotential surface at Titan is radially shifted by $\Phi_{e} / g_{s}$ with $g_{s}$ the surface gravity.

In general, the satellite's tidal response depends on its interior structure, thermal state, tidally effective rheology, and the frequency of tidal forcing, and is parameterized in terms of the degree-2 body tide Love numbers $h_{2}, k_{2}$, and $I_{2}$. We assume that the satellite's outer ice shell responds elastically to the tidal forces exerted by Saturn. This assumption is justified since diurnal tidal stresses are stored mostly elastically in the cold, stagnant outermost part of the ice shell and is widely insensitive to the specific rheology and thickness of the ice shell [Wahr et al., 2009; Jara-Orué and Vermeersen, 2011]. We solve for the radial displacement Love number $h_{2}$, the potential Love number $k_{2}$, and the Shida number $I_{2}$ by numerical integration of the linearized field equations for small elastic deformations in a spherical, incompressible, and self-gravitating body, accounting for certain continuity and boundary conditions [see Segatz et al., 1988; Hussmann et al., 2011 , and references therein]. As model inputs we use the calculated radial profiles of density and elastic moduli as described in section 2.1.The ocean is modeled as an inviscid fluid layer by assuming a low rigidity and low viscosity while making sure that the tidal response is short as compared to the corresponding Maxwell time defined by the ratio of steady state viscosity and rigidity. For detailed descriptions of more general cases such as radially stratified, viscoelastic, and self-gravitating spherical body and the solution of the equivalent elastic problem in the frequency domain, we refer the reader to Cheng and Toksöz [1978], Wahr et al. [2009], Jara-Orué and Vermeersen [2011], and Beuthe [2013].

Since we are interested in global amplitude patterns of diurnal tidal stresses, we calculate the maximum tensile (areal) stress [Zürn and Wilhelm, 1984]

$$
\sigma_{\text {areal }}=\frac{1}{2}\left(\sigma_{\theta \theta}+\sigma_{\phi \phi}\right)
$$

and maximum shear stress

$$
\tau_{\text {shear }}=\left[\left(\frac{\sigma_{\theta \theta}-\sigma_{\phi \phi}}{2}\right)^{2}+\tau_{\theta \phi}^{2}\right]^{1 / 2}
$$

at Titan's surface, whereas the mean tidal stress $\bar{\sigma}_{\text {tide }}$ is given by

$$
\bar{\sigma}_{\text {tide }}=\left[\frac{1}{2}\left(\sigma_{\theta \theta}^{2}+\sigma_{\phi \phi}^{2}+2 \tau_{\theta \phi}^{2}\right)\right]^{1 / 2} .
$$

The diurnal tidal stresses $\sigma_{\theta \theta}, \sigma_{\phi \phi}$ and $\tau_{\theta \phi}=\tau_{\phi \theta}$ are specified by the nonzero components of the stress tensor in latitudinal $\left(\sigma_{\theta \theta}\right)$, longitudinal $\left(\sigma_{\phi \phi}\right)$, and cross directions $\left(\tau_{\theta \phi}=\tau_{\phi \theta}\right)$ and related to the time-variable tidal potential $\Phi_{e}$ at the satellite's surface (see Appendix E).

\section{Interior Structure and Tidal Stresses}

We have constructed 60 models of Titan's present interior structure. Shown in Figure 2 are color-coded thicknesses of Titan's icy crust, $d_{c^{\prime}}$ and its subsurface water-ammonia ocean underneath, $d_{o}$, as a function of the satellite's degree-2 body tide Love number $k_{2}$ and mean moment-of-inertia factor Mol, respectively. In general, structural information, i.e., Mol, $k_{2}$, and radial extent of outer ice shell (Figure 2a) and subsurface ocean (Figure $2 \mathrm{~b}$ ), is conveyed by the figure axes and color scale, whereas additional information about the bulk chemistry, i.e., $\mathrm{NH}_{3}$ content and average core density, is encoded through symbol shape and size.

In Figure 2a, it can be distinguished between thin (bluish), intermediate (greenish), and thick (reddish) outer ice shells. They correspond, respectively, to deep (reddish), intermediate (turquoise), and shallow (bluish) 

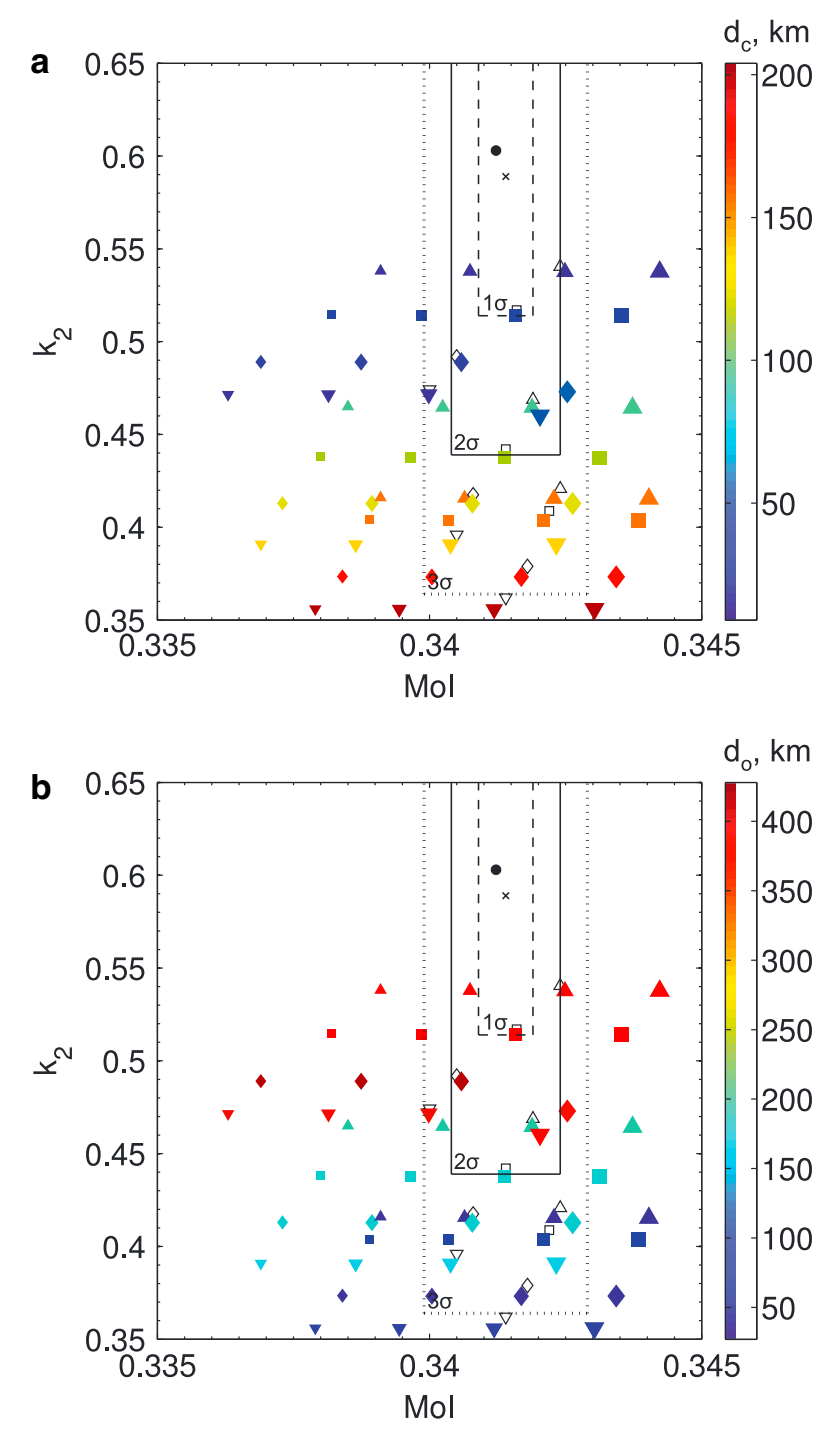

Figure 2. Model determinations of (a) crustal thickness $d_{c}$ and (b) subsurface ocean thickness $d_{o}$ as a function of moment-of-inertia factor Mol and degree-2 Love number $k_{2}$ within their observational uncertainties of $1 \sigma$ (dashed), $2 \sigma$ (solid), and $3 \sigma$ (dotted) according to solution 1 of less et al. [2012], $k_{2}=0.589 \pm 0.15(2 \sigma)$. The black cross denotes the center of the boxes, and the black dot represents the ammonium sulfate $\left(\left(\mathrm{NH}_{4}\right)_{2} \mathrm{SO}_{4}\right)$ ocean case [Fortes et al., 2007]. See text for further details. subsurface water-ammonia oceans shown in Figure 2b. Furthermore, form and size of each symbol represent specific ammonia $\left(\mathrm{NH}_{3}\right)$ contents within the subsurface ocean and average densities of the silicate core, respectively. From top to bottom, the pyramid, square, diamond, and triangle marks denote an increase in $\mathrm{NH}_{3}$ concentration varying among $0,5,15$, and $25 \mathrm{wt} \%$. From left to right, core density decreases with increasing symbol size.

Filled symbols represent models with a water-ice crust, while open symbols correspond to cases with a crust composed of water-ice and methane clathrate in equal amounts by mass. The latter are shifted slightly to larger values of $k_{2}$ and Mol with respect to the former, thereby indicating that methane-clathrate crusts tend to be denser and less rigid than pure water-ice crust layers. This becomes even more pronounced with increasing thickness of Titan's outer ice shell. It is seen that $k_{2}$ is strongly related to both the crustal thickness $d_{c}$ and the subsurface ocean thickness $d_{o}$, respectively. With increasing ocean density, e.g., in the presence of salty constituents and/or suspended sediment loads, valid models will be shifted to even larger $k_{2}$ values, thereby allowing for thicker outer ice shells. In terms of interior structure, we obtain similar results if the ammonia-water ocean is replaced by a saltwater ocean with an $\mathrm{NaCl}$ content of 5 wt $\%$ (ocean density $1.15 \mathrm{~g} \mathrm{~cm}^{-3}$ ), similar to terrestrial oceans.

Since extensive leaching of Titan's hydrated silicate core cannot be excluded, we show in Figure 2 an example for a dense ocean composed of ammonium sulfate $\left(\left(\mathrm{NH}_{4}\right)_{2} \mathrm{SO}_{4}\right)$ (density $1.35 \mathrm{~g} \mathrm{~cm}^{-3}$ ) based on a model proposed by Fortes et al. [2007]. Solutes leached from the hydrated silicate core (e.g., $\mathrm{Cl}^{-}, \mathrm{HCO}_{3}^{-}, \mathrm{SO}_{4}^{2-}, \mathrm{Na}^{+}, \mathrm{Ca}^{2+}, \mathrm{Mg}^{2+}$ ) could increase the density of Titan's subsurface water ocean. However, a number of hydrated salts would precipitate again upon ocean freezing and sink to the ocean floor. It must be also taken into account that the concentration of solutes in subsurface water oceans is probably significantly less than $10 \mathrm{wt} \%$ [e.g., Tobie et al., 2012] with only little effect on the density of the liquid. As a consequence, melting point reduction by ammonia-water solutions is a valid explanation to facilitate the possible existence of liquid water subsurface reservoirs on icy bodies in the outer solar system [e.g., Sohl et al., 2010].

In general, models yielding thinner crusts and substantial subsurface oceans are found to correspond to larger body tide Love numbers $k_{2}$ and vice versa. Largely extended icy crusts can be ruled out, however, since models with ice shell thicknesses of more than $110 \mathrm{~km}$ are difficult to reconcile with the observational constraints imposed by the Cassini gravitational field data (black boxes) [less et al., 2010, 2012]. In turn, valid models of Titan produce subsurface oceans that are at least $180 \mathrm{~km}$ thick. This is illustrated in Figure 3 , in 


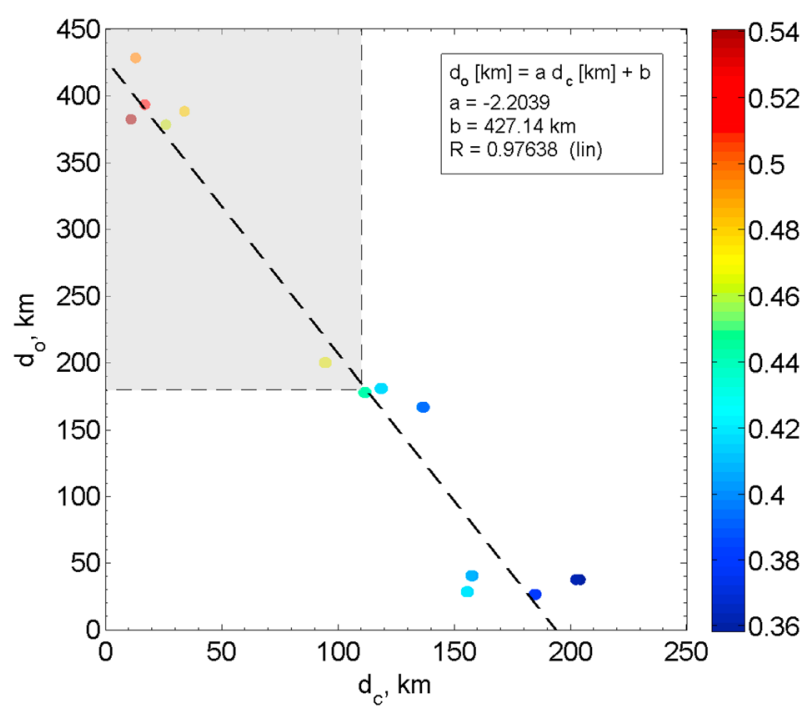

Figure 3. Degree-2 Love number $k_{2}$ (color coded) as a function of thickness for outer ice shell $d_{c}$ and subsurface ocean $d_{o}$, respectively. Shown are only models compliant with the $2 \sigma$ constraint imposed on the moment-of-inertia factor Mol. The shaded box illustrates the range in which models also fulfill the $2 \sigma$ observational uncertainties of $k_{2}$. which we explicitly show how the calculated body tide Love numbers $k_{2}$ depend on the thicknesses of both outer ice shell and subsurface water-ammonia ocean. It is even possible to construct valid models with subsurface oceans of about $430 \mathrm{~km}$ thickness, corresponding to structural models with vanishing high-pressure water-ice layers between the silicate core and the liquid ocean itself. In other words, in these cases the subsurface ocean were in direct contact with the silicate core with important implications for Titan's habitable potential [Castillo-Rogez and Lunine, 2010; Fortes, 2012].

Furthermore, inspection of the symbols and their sizes in Figure 2 reveals that Titan's Mol factor is partly controlled by the density of the silicate core, shifting to larger Mol values with decreasing core density. For example, the satellite's moment of inertia will increase if less dense material is added

to the core because of the smaller density contrast between the surface and the deep interior. In the presence of a subsurface ocean, the density distribution within the silicate core has a negligible effect on the body tide Love number $k_{2}$, owing to the mechanical decoupling of the outer ice shell from the deep interior.

Moreover, the ammonia $\left(\mathrm{NH}_{3}\right)$ concentration within the subsurface ocean provides bounds on the ocean

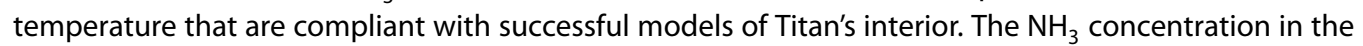
ocean (represented by the form of a symbol) likewise affects the Mol factor and the degree-2 body tide Love number $k_{2}$. It is seen from inspection of Figures $2 \mathrm{a}$ and $2 \mathrm{~b}$ that for lower $\mathrm{NH}_{3}$ concentrations the symbols shift to larger values of each Mol and $k_{2}$. For models corresponding to rather deep oceans with thicknesses of at least $370 \mathrm{~km}$ and relatively thin outer ice shells a few tens of kilometers thick, no firm constraints on the ocean composition (in terms of $\mathrm{NH}_{3}$ content) can be imposed with respect to the reported $2 \sigma$ error margins of $\mathrm{Mol}$ and $k_{2}$, respectively. Depending on the actual $\mathrm{NH}_{3}$ content, ocean temperatures down to $220 \mathrm{~K}$ are possible for $\mathrm{NH}_{3}$ concentrations up to $25 \mathrm{wt} \%$. However, models with intermediate-sized oceans of about $200 \mathrm{~km}$ depth and significant ice shells with thicknesses of about $100 \mathrm{~km}$ satisfy these observational constraints only if low $\mathrm{NH}_{3}$ concentrations in the range of 0 to $5 \mathrm{wt} \%$ are present, corresponding to relatively warm oceans with temperatures in excess of $255 \mathrm{~K}$.

We consider the reference model illustrated in Figure 4 as a plausible fiducial model of Titan's present interior structure that satisfies the $2 \sigma$ observational data of the Mol factor and the degree-2 body tide Love number $k_{2}$ based on Cassini gravity data. The model parameters are summarized in Table 3 . The construction of the reference temperature profile requires three fixpoints, namely, the ocean temperature (prescribed), the surface temperature $(94 \mathrm{~K})$, and the central temperature $(900 \mathrm{~K})$. We then vary two core parameters-the effective specific heat production and the average viscosity — such that (i) the central temperature in the core stays below the critical temperature of silicate dehydration and (ii) the mean surface temperature of Titan is met. The calculated values of the Mol factor and the degree- 2 body tide Love number $k_{2}$ are 0.34 and 0.44 , respectively, commensurate with the low end of the reported $2 \sigma$ error margins of the latter [less et al., 2012]. The silicate core is about $2080 \mathrm{~km}$ in radius with an average density of $2.55 \mathrm{~g} \mathrm{~cm}^{-3}$. This is in good agreement with the core radius range of 1980 to $2120 \mathrm{~km}$ and the corresponding density range of 2.57 to $2.46 \mathrm{~g} \mathrm{~cm}^{-3}$ obtained by Fortes [2012] for a broad suite of compositional models of Titan's interior. The specific heat production rate of the core is about half of that what would be expected for a chondritic bulk composition, consistent with the early leaching of radioactive isotopes [Castillo-Rogez and Lunine, 2010]. While the central pressure is $4.9 \mathrm{GPa}$, the pressure at the core-mantle boundary is about $0.8 \mathrm{GPa}$. A significant 

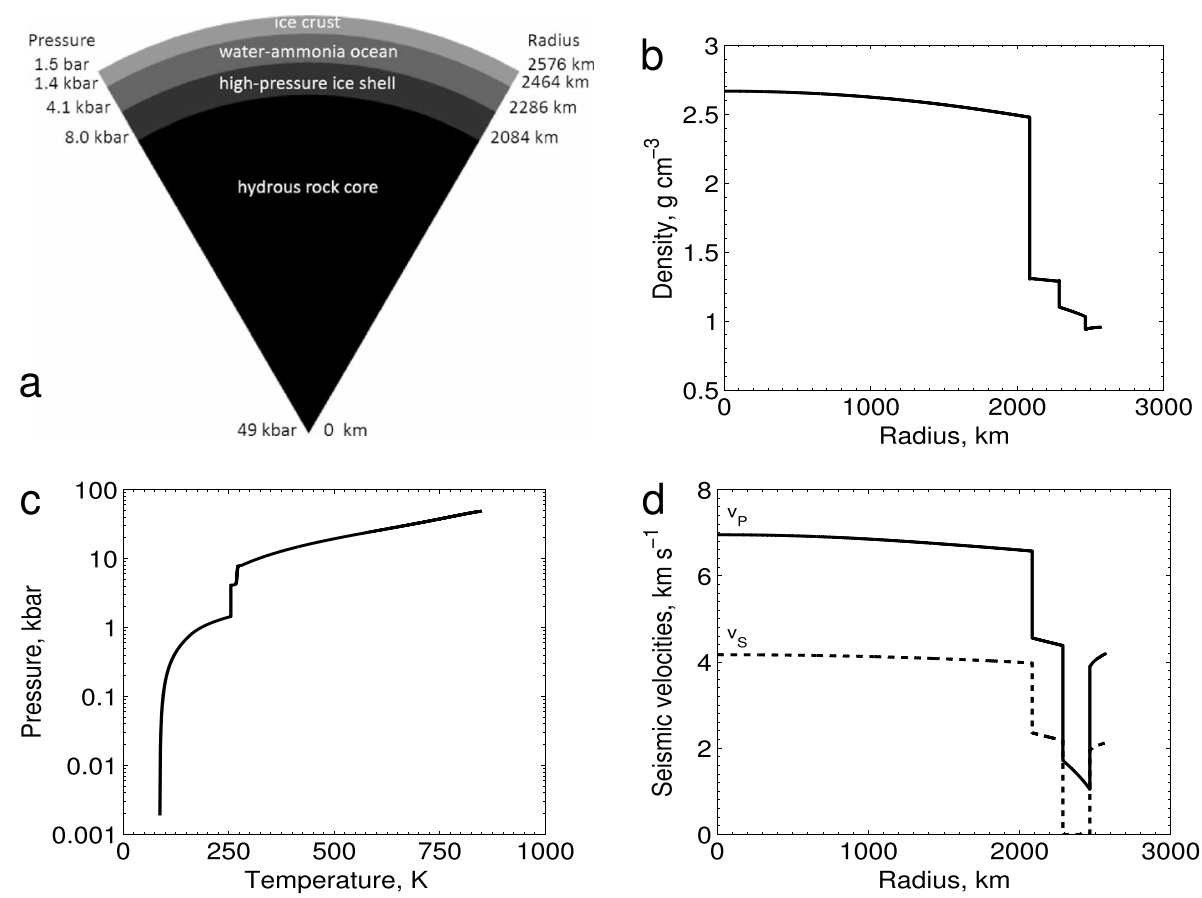

Figure 4. Reference model of Titan's interior structure used in the present study: (a) radial structure, (b) density distribution, (c) temperature-pressure diagram, and (d) seismic velocities.

high-pressure water-ice layer about $200 \mathrm{~km}$ in thickness with an average density of $1.3 \mathrm{~g} \mathrm{~cm}^{-3}$ is retained. For the subsurface water-ammonia $\left(\mathrm{H}_{2} \mathrm{O}-\mathrm{NH}_{3}\right)$ ocean we obtain a thickness of about $180 \mathrm{~km}$. The average ocean density is $1.1 \mathrm{~g} \mathrm{~cm}^{-3}$. The ocean temperature is $255 \mathrm{~K}$ at an $\mathrm{NH}_{3}$ content of $5 \mathrm{wt} \%$. The outer ice shell is $110 \mathrm{~km}$ thick with an average density of $0.95 \mathrm{~g} \mathrm{~cm}^{-3}$, in agreement with compensated floating ice shell

Table 3. Structural Parameters of the Reference Model

\begin{tabular}{|c|c|c|c|}
\hline Parameter & Symbol & Unit & Value \\
\hline Core mass fraction & CMF & wt \% & 72.0 \\
\hline Specific heat production rate & $\epsilon$ & $10^{-12} \mathrm{~W} \mathrm{~kg}^{-1}$ & 2.3 \\
\hline Core viscosity & $\eta_{r}$ & Pa s & $10^{25}$ \\
\hline Central pressure & $P_{0}$ & GPa & 4.88 \\
\hline Pressure core-mantle boundary & $P_{\mathrm{cmb}}$ & GPa & 0.798 \\
\hline Moment-of-inertia factor & Mol & - & 0.340 \\
\hline Degree-2 tidal potential Love number & $k_{2}$ & - & 0.437 \\
\hline Degree- 2 radial displacement Love number & $h_{2}$ & - & 1.29 \\
\hline Degree-2 Shida number & $I_{2}$ & - & 0.336 \\
\hline Tidal strain factor & $s_{2}$ & - & 0.564 \\
\hline Core radius & $R_{r}$ & $\mathrm{~km}$ & 2084 \\
\hline Thickness high-pressure ice shell & $d_{i}$ & $\mathrm{~km}$ & 202 \\
\hline Thickness subsurface ocean & $d_{0}$ & $\mathrm{~km}$ & 178 \\
\hline Thickness outer ice shell & $d_{c}$ & $\mathrm{~km}$ & 111 \\
\hline Heat flux core mantle boundary & $q_{\mathrm{cmb}}$ & $\mathrm{mW} \mathrm{m} \mathrm{m}^{-2}$ & 4.08 \\
\hline Heat flux (in the) ocean & $q_{\text {in }}$ & $\mathrm{mW} \mathrm{m} \mathrm{m}^{-2}$ & 3.94 \\
\hline Heat flux (out of the) ocean & $q_{\text {out }}$ & $\mathrm{mW} \mathrm{m} \mathrm{m}^{-2}$ & 3.39 \\
\hline Surface heat flux & $q_{s}$ & $\mathrm{~mW} \mathrm{~m} \mathrm{~m}^{-2}$ & 3.11 \\
\hline Density silicate core & $\rho_{r}$ & $\mathrm{~g} \mathrm{~cm}^{-3}$ & 2.55 \\
\hline Density high-pressure ice shell & $\rho_{i}$ & $\mathrm{~g} \mathrm{~cm}^{-3}$ & 1.30 \\
\hline Density subsurface ocean & $\rho_{0}$ & $\mathrm{~g} \mathrm{~cm}^{-3}$ & 1.07 \\
\hline Density outer ice shell & $\rho_{c}$ & $\mathrm{~g} \mathrm{~cm}^{-3}$ & 0.951 \\
\hline Rigidity silicate core & $\mu_{r}$ & $\mathrm{GPa}$ & 42.1 \\
\hline Rigidity high-pressure ice shell & $\mu_{i}$ & $\mathrm{GPa}$ & 6.66 \\
\hline Rigidity subsurface ocean & $\mu_{0}$ & $\mathrm{GPa}$ & 0. \\
\hline Rigidity outer ice shell & $\mu_{c}$ & $\mathrm{GPa}$ & 4.05 \\
\hline
\end{tabular}



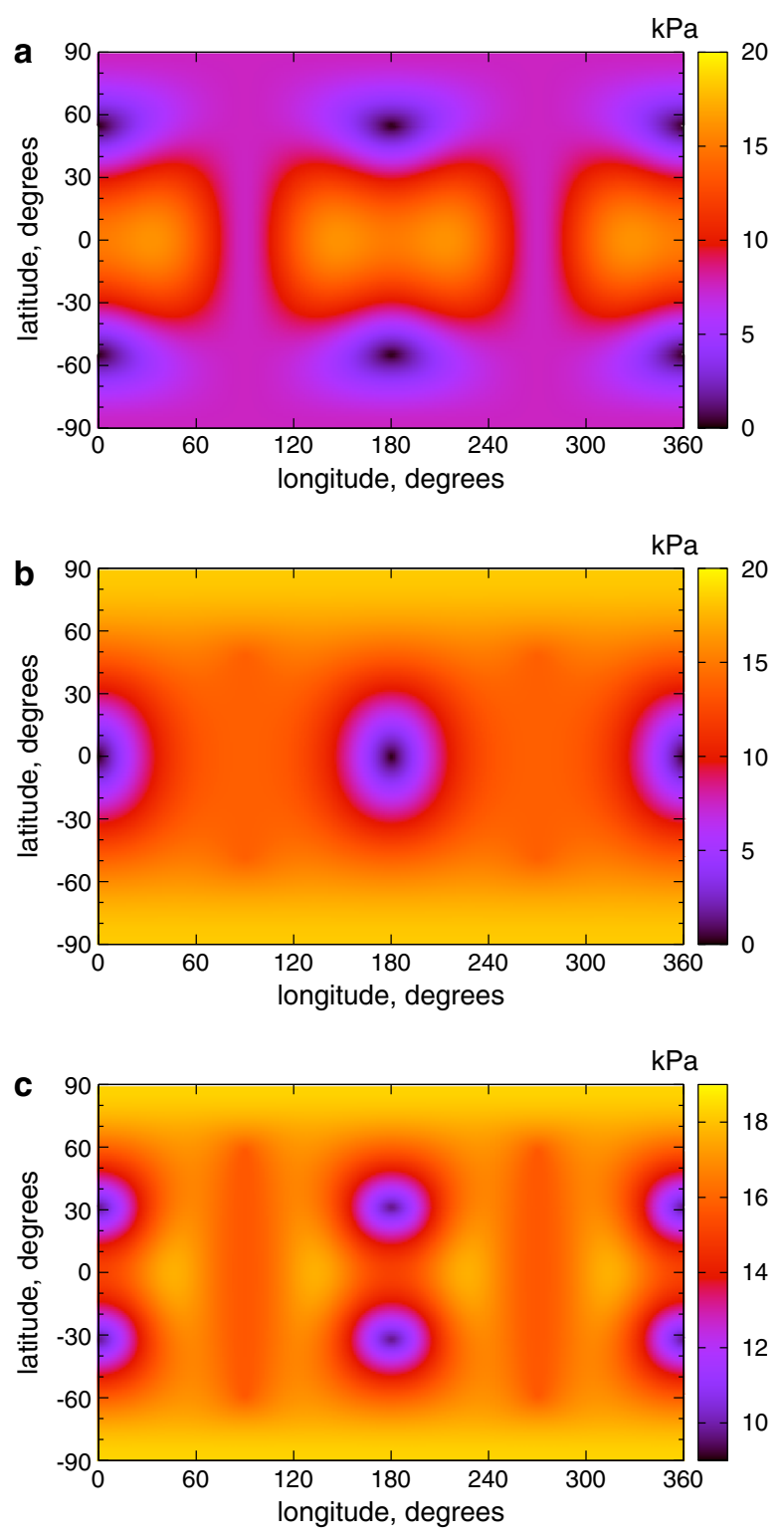

Figure 5. Global amplitude patterns of (a) maximum tensile stresses, $\sigma_{\text {areal }} ;$ (b) maximum shear stresses, $\tau_{\text {shear }}$; and (c) maximum diurnal tidal stresses, $\bar{\sigma}_{\text {tide, }}$ color coded in units of $\mathrm{kPa}$. The maximum shear stresses are concentrated in the polar areas, while the maximum tensile stresses predominate in the near-equatorial, midlatitude areas of the sub- and anti-Saturnian hemispheres.

geologic surface features observed on Earth and on Titan [Solomonidou et al., 2013]. For example, the presence of extensive dune fields [e.g., Radebaugh et al., 2008] is indicative of aeolian processes predominating close to the surface, while drainage networks and lakes [Stofan et al., 2007] are likely related to precipitation and fluvial phenomena or subsurface reservoirs as part of Titan's alkanological cycle [e.g., Atreya et al., 2006; Lebreton et al., 2009].

Table 4 lists reported observations of features on Titan's surface that could be related to endogenic activity. The morphologies, shapes, and locations of these surface expressions are informative about the underlying formation processes at work within the corresponding geologic terrains. It has been suggested that Titan's rigid icy crust could be assembled in the form of ice rafts reminiscent to terrestrial tectonic plates [e.g., Mitri et al., 2010]. In the same vein, terrestrial phenomena like volcanism and/or the formation of linear features and drainage networks controlled by tectonics could also exist on Titan [e.g., Burr et al., 2009; Lopes et al., 
Table 4. Tectonic-Like and Volcanic-Like Features on Titan

\begin{tabular}{|c|c|c|c|}
\hline Location & Name & Description & Tectonic-Like Features \\
\hline $57^{\circ} \mathrm{N}, 62^{\circ} \mathrm{W}$ & Misty Montes & ${ }^{a}$ Mountain chain & RADAR bright-dark pairing (T23/Jan 2007) \\
\hline $52^{\circ} \mathrm{N}, 347^{\circ} \mathrm{W}$ & - & ${ }^{\mathrm{b}}$ Mountain block & $\begin{array}{l}1400 \mathrm{~m} \text { elevation from the surroundings } \\
\text { (T30/May 2007) }\end{array}$ \\
\hline $47^{\circ} \mathrm{N}, 39.5^{\circ} \mathrm{W}$ & Rohe Fluctus & $c, \mathrm{~d}$ Flow-like feature & $\begin{array}{l}\text { Bright-rimmed, oval-shaped caldera } \\
\text { (TA/Oct 2004-T3/Feb 2005) }\end{array}$ \\
\hline $40^{\circ} \mathrm{N}, 118^{\circ} \mathrm{W}$ & Ara Fluctus & $c, d$ Flow-like feature & Noncircular depression (T3/Feb 2005) \\
\hline $20^{\circ} \mathrm{N}, 87^{\circ} \mathrm{W}$ & - & e Ridges & Interplay with lineaments (T3/Feb 2005) \\
\hline $20^{\circ} \mathrm{N}, 70^{\circ} \mathrm{W}$ & T3 flows & c,fFlow-like feature & Flowing downhill (T3/Feb 2005) \\
\hline $10^{\circ} \mathrm{N}, 15^{\circ} \mathrm{W}$ & - & ${ }^{9}$ Blocks of mountains & Linear morphology (T3/Feb 2005) \\
\hline $15^{\circ} \mathrm{N}, 45^{\circ} \mathrm{W}$ & - & gBlocks of mountains & Linear morphology (T3/Feb 2005) \\
\hline $0^{\circ} \mathrm{N}, 180^{\circ} \mathrm{W}$ & - & $\mathrm{h}_{\text {Joints and/or faults }}$ & $\begin{array}{l}\text { Rectangular drainage classification } \\
\text { (T13/Apr 2006-T44/May 2008) }\end{array}$ \\
\hline $10^{\circ} \mathrm{S}, 145^{\circ} \mathrm{W}$ & - & $\mathrm{h}_{\text {Joints and/or faults }}$ & $\begin{array}{l}\text { Rectangular drainage classification } \\
\text { (T13/Apr 2006-T44/May 2008) }\end{array}$ \\
\hline $2^{\circ} \mathrm{S}, 127^{\circ} \mathrm{W}$ & - & ${ }^{b}$ Ridges & Parallel formations (T43/May 2008) \\
\hline $5^{\circ}-12.5^{\circ} \mathrm{S}, 63^{\circ}-67^{\circ} \mathrm{W}$ & - & b,g,i Curvilinear mountains; ridges & Linear-like traces (T8/Oct 2005) \\
\hline $10^{\circ} \mathrm{S}, 210^{\circ} \mathrm{W}$ & - & ${ }^{\mathrm{j}}$ Mountainous region & (T9/Dec 2005-T13/Apr 2006) \\
\hline $10^{\circ} \mathrm{S}, 140^{\circ} \mathrm{W}$ & Western Xanadu flows & $c, k_{F l o w}$-like feature & (T13/Apr 2006) \\
\hline $10^{\circ} \mathrm{S}, 192^{\circ} \mathrm{W}$ & - & $\mathrm{m}_{\text {Linear fault patterns; canyon-like formations }}$ & Linear faults (Huygens-DISR/Jan 2005) \\
\hline $10.4^{\circ} \mathrm{S}, 192.4^{\circ} \mathrm{W}$ & - & l,mRidges & (Huygens-DISR/Jan 2005) \\
\hline $12^{\circ} \mathrm{S}, 38.5^{\circ} \mathrm{W}$ & Mohini Fluctus & ${ }^{C}$ Lobate flows & (T25/Feb 2007-T28/Mar 2007) \\
\hline $14.5^{\circ} \mathrm{S}, 40.5^{\circ} \mathrm{W}$ & Doom Mons & 'Volcanic-like peak & $\begin{array}{c}\text { Topographic high, mountain-like structure } \\
\text { (T25/Feb 2007-T28/Mar 2007) }\end{array}$ \\
\hline $14.5^{\circ} \mathrm{S}, 40^{\circ} \mathrm{W}$ & Sotra Patera & ${ }^{\mathrm{C}}$ Deep pit & Ovoid caldera/pit (T25/Feb 2007-T28/Mar 2007) \\
\hline $15^{\circ} \mathrm{S}, 100^{\circ} \mathrm{W}$ & - & ${ }^{n}$ Lithospheric fault-blocks & (model) \\
\hline $15^{\circ} \mathrm{S}, 155^{\circ} \mathrm{W}$ & - & ${ }^{\circ}$ Conjugate-like faults & $\begin{array}{l}\text { Trending lineaments } \\
\text { (T0/Jul 2004-TA/Oct 2004-TB/Dec 2004) }\end{array}$ \\
\hline $20^{\circ} \mathrm{S}, 130^{\circ} \mathrm{W}$ & Tui Regio & $c, p$ Flow-like region & $\begin{array}{l}\text { Trending dark linear marks on VIMS data } \\
\text { (TA/Oct 2004-TB/Dec 2004) }\end{array}$ \\
\hline $26^{\circ} \mathrm{S}, 78^{\circ} \mathrm{W}$ & Hotei Regio & $c, q$ Volcanic-like terrain; radial fault system & Circular tectonic features (T47/Nov 2008) \\
\hline $30^{\circ} \mathrm{S}, 107^{\circ} \mathrm{W}$ & - & ${ }^{\mathrm{b}}$ Mountains & (T43/May 2008) \\
\hline $30^{\circ} \mathrm{S}, 315^{\circ} \mathrm{W}$ & - & ${ }^{r}$ Mountain ranges & Lineaments with tectonic control (T20/Oct 2006) \\
\hline $40^{\circ} \mathrm{S}, 340^{\circ} \mathrm{W}$ & - & ${ }^{\mathrm{s}}$ Hills & (T7/Sep 2005) \\
\hline
\end{tabular}

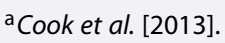

${ }^{\mathrm{b}}$ Mitri et al. [2010].

'Lopes et al. [2013].

d Lopes et al. [2007].

eWilliams et al. [2011].

fLe Corre et al. [2009].

${ }^{g}$ Radebaugh et al. [2007].

${ }^{\mathrm{h}}$ Burr et al. [2009].

'Lopes et al. [2010].

jBarnes et al. [2007].

kWall et al. [2009].

'Tomasko et al. [2005].

$\mathrm{m}_{\text {Soderblom et al. [2007]. }}$

${ }^{n}$ Radebaugh et al. [2011].

o Porco et al. [2005].

p Barnes et al. [2006].

qSoderblom et al. [2009].

'Sotin et al. [2007].

sLunine et al. [2008].

2013]. The tectonic-like origin of surface expressions like mountains, faults, and volcanic structures are suggestively related to ice rafts of altered densities moving on a liquid layer, thereby producing convergent or divergent surface features due to stresses caused by endogenic activity. In any event, it cannot be excluded that endogenic dynamics has played an important role for Titan's geologic activity.

Additional types of surface features that are particularly interesting due to their uncertain formation history are those that seem to be surface expressions of Titan's possible internal activity, i.e., geologic structures 


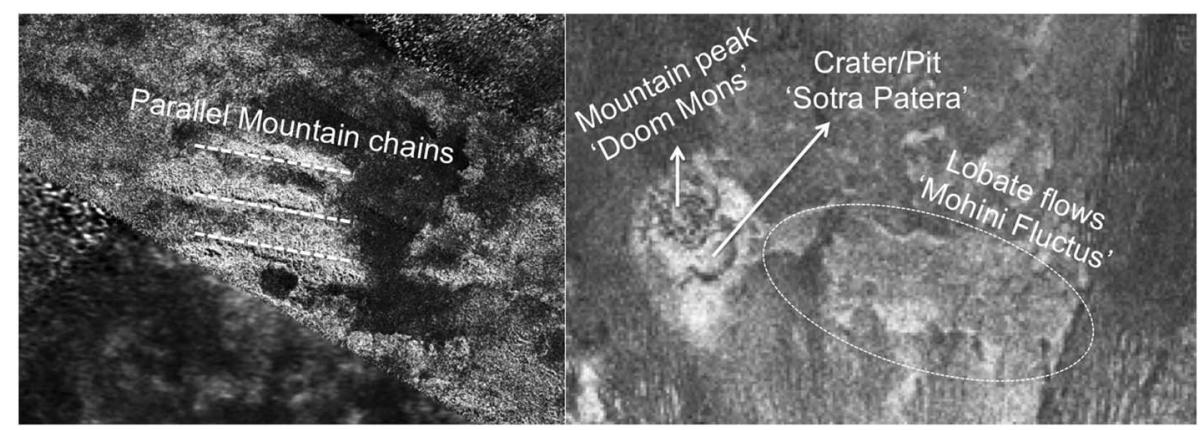

Figure 6. Possible tectonic and volcanic features on Titan. (left) Parallel mountain chains $\left(2^{\circ} \mathrm{S}, 127^{\circ} \mathrm{W}\right)$ almost up to $2 \mathrm{~km}$ in height, formed possibly due to folding of the upper crust (tectonic-like motion) (Image credit: NASA/JPL-Caltech). (right) A possible cryovolcanic area, named Sotra Patera $\left(15^{\circ} \mathrm{S}, 40^{\circ} \mathrm{W}\right)$, consisting of subareas with volcanic-like features such as a pit crater and lobate flows [Lopes et al., 2013] (Image credit: NASA/JPL-Caltech/ASI).

resulting from upwelling or fracturing of the upper crust caused by endogenic dynamics. Representative features of this type are morphotectonic features [Solomonidou et al., 2013] and candidate cryovolcanic sites (Figure 6). Cryovolcanism has been hypothesized on Titan as a means of replenishing methane in Titan's atmosphere [e.g., Tobie et al., 2006], and it can also explain changes reported in surface brightness or morphologically volcanic-like features [e.g., Lopes et al., 2007; Soderblom et al., 2009; Lopes et al., 2013; Solomonidou et al., 2013]. Other possibilities to explain these surface expressions prefer exogenic formation processes such as fluvial or lacustrine [Barnes et al., 2011; Moore and Howard, 2010; Moore and Pappalardo, 2011].

In any event, some areas on Titan's surface are likely to have exhibited brightness changes over time (cryovolcanic candidates) and/or have morphologies closely related to Earth's tectonic manifestations (e.g., mountains, faults). They are mostly located at equatorial latitudes between $30^{\circ} \mathrm{S}$ and $30^{\circ} \mathrm{N}$ and are likely associated with the surface stress field [Soderblom et al., 2009; Lopes et al., 2013; Solomonidou et al., 2013]. The mountainous regions were found to have elevations from 200 to $2000 \mathrm{~m}$ [Radebaugh et al., 2007; Mitri et al., 2010; Lorenz et al., 2013] and are characterized as mountain chains, hills, and ridges depending on their size, shape, and extension (see Table 4 and Figure 6 (left)). On Earth such features are mainly attributed to lateral motions of lithospheric plates, a geologic phenomenon that is largely unlikely to occur on Titan in the same fashion as it does on Earth. In spite of being a consequence of crustal movements, some blocks of mountains may have originated from impact ejecta [Radebaugh et al., 2007].

Other interesting areas on Titan are the so-called "active" regions with reported changes in brightness and/or color over time [Nelson et al., 2009; Wall et al., 2009]. In Table 4 the characteristics of these cryovolcanic candidate sites are listed, among which are Tui Regio $\left(20^{\circ} \mathrm{S}, 130^{\circ} \mathrm{W}\right)$, a $1500 \mathrm{~km}$ long flow-like figure [Barnes et al., 2006], Hotei Regio $\left(26^{\circ} \mathrm{S}, 78^{\circ} \mathrm{W}\right)$, a $700 \mathrm{~km}$ wide volcanic-like terrain [Soderblom et al., 2009], and Sotra Patera region $\left(15^{\circ} \mathrm{S}, 40^{\circ} \mathrm{W}\right.$ ) (formerly known as Sotra Facula), and currently including Mohini Fluctus, Doom Mons, and the Sotra Patera pit [Lopes et al., 2010, 2013]. These areas together with others (see Table 4) have anomalous spectral and morphological properties that are possibly caused by dynamic geologic processes [Jaumann et al., 2009; Lopes et al., 2010, 2013]. Among others, deep craters (Sotra Patera), lobate flows (Mohini Fluctus), and caldera-like formations (in Hotei Regio) have been observed by Cassini RADAR and VIMS. In addition, VIMS data processing provided indications for brightness or surface albedo variations within a period of one to 3.5 years.

In analogy with terrestrial morphotectonic structures, the shape, size, and morphology of Titan's observed mountains, ridges, hills, and linear features such as faults, major fractures, and canyons probably originate through some form of compressional and extensional tectonic activity. Titan's rigid outer ice shell and the probable existence of a subsurface ocean create an analogy with terrestrial, at least surficial, plate tectonics. In this work, we have focused on the possible relations between solid body tides on Titan and observed geologic features on Titan's surface. Shown in Figure 7 is a map including both the diurnal tidal stress and geologic information. On this map we see the morphotectonic features of Titan which are the current identified major types of tectonic-like features (see Table 4) and their distribution on the surface. These are the elevated features such as mountains (green), faults and fractures (blue), and the candidate cryovolcanic 


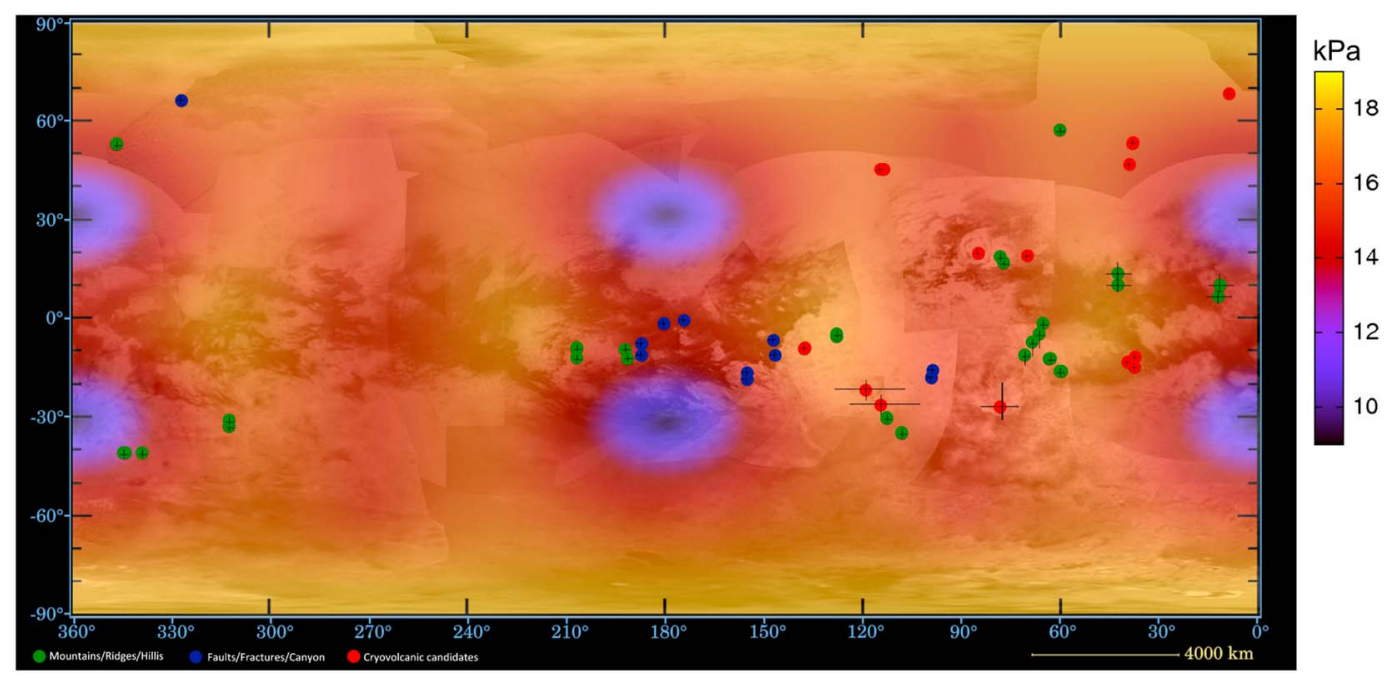

Figure 7. Global amplitude pattern of maximum diurnal tidal stresses, $\bar{\sigma}_{\text {tide }}$, color coded in units of kPa (Figure $5 \mathrm{c}$ ) overlaid onto a base map of Titan's surface produced from Cassini ISS images (PIA14908 background map credit: NASA/JPL-Caltech/Space Science Institute). Symbols indicate characteristic geologic features possibly related to tectonics on Titan. Mountains and ridges (green), linear features such as faults and fractures (blue), candidate cryovolcanic features (red).

features (red). On this map is also overplotted the global amplitude pattern of maximum diurnal tidal stresses, $\bar{\sigma}_{\text {tide, }}$ as shown in Figure $5 c$. This map reveals the correlation between features that are possibly tectonic and/or volcanic in origin and zones of intense tide-induced surface deformation concentrated at midlatitudes.

Four midlatitudes $\left(50^{\circ} \mathrm{S}\right.$ to $\left.50^{\circ} \mathrm{N}\right)$ centered at (a) $40^{\circ}$, (b) $120^{\circ}$, (c) $230^{\circ}$, and (d) $310^{\circ}$ west longitude, respectively, are the most amplified ones in terms of tidal flexure and stress accumulation, indicating zones of potentially high internal influence (Figure 7). As seen in the overplotted maps, we find that most of the sites listed in Table 4 are located within $\pm 30^{\circ}$ latitude from the equator in the leading hemisphere and therefore preferentially located within the strongly tidally flexed zones. This is particularly true for the mountains and the cryovolcanic candidates, while exceptions mainly concern the faults (blue dots on the map of Figure 7) and a couple of highlands in the high northern latitudes around $60^{\circ} \mathrm{N}$. We note that the volcanic-like sites are concentrated in strongly tidally flexed zones as follows: Sotra Patera is located in the center of the (a) zone, confirming suggestions that rank this area as the most favorable candidate cryovolcanic region [Lopes et al., 2013]; Tui Regio is located within the limits of the (b) zone; and Hotei Regio is located on the border between these two zones of amplified tidal distortion.

\section{Discussion and Conclusions}

We have studied present-day structural models of Titan's interior that are consistent with Cassini gravitational field data and simultaneously satisfy the satellite's inferred axial moment-of-inertia factor and degree-2 body tide Love number $k_{2}$ at the low end of the reported error margins of the latter [less et al., 2012]. In order to explain larger $k_{2}$ values than the average of the measured $k_{2}$, one may invoke ad hoc density hypotheses such as (i) relatively dense liquids [e.g., Mitri et al., 2014] or (ii) mushy lower ice layers, but their possible existence is not supported by observations at this point. The first class of models has the difficulty that oceans composed of almost saturated salty solutions or suspensions were required, resulting in the precipitation of dense or suspended constituents over time. On the other hand, the existence of a mushy ice layer on Titan would result in a phase shift between primary and secondary tidal potential that to our knowledge is not supported by Cassini gravity field observations. More accurate time-variable gravity field data are required to resolve this issue.

Amplitude patterns of both diurnal tidal tensile and shear stresses and their superposition were calculated and are compared to the spatial distribution of tentative volcanic-like and tectonic-like surface features on Titan. Though alternative explanations prefer an exogenic origin [e.g., Moore and Pappalardo, 2011], the correlation between the tidal stress patterns illustrated in Figure 7 and the surface features seen on Titan may 
rather suggest an endogenic origin of the latter. The calculated diurnal tidal stresses are on the order of a few tens of $\mathrm{kPa}$, comparable to the magnitude of maximum possible nonhydrostatic deviatoric stresses on Titan [Gao and Stevenson, 2013], but the accumulation of tectonic stresses could eventually help exceed the tensile strength of fractured ice [Kimura et al., 2007; Smith-Konter and Pappalardo, 2008]. True polar wander of the spin axis due to large-scale redistribution of mass on the surface or within the interior and nonsynchronous rotation of the decoupled shell moving slowly across the satellite's permanent tidal bulge may cause the buildup of long-term stresses and the formation of geologic surface features on a global scale [e.g., Jara-Orué and Vermeersen, 2011, and references therein]. Furthermore, in the event of stress hysteresis owing to transient creep phenomena [e.g., Shoji et al., 2013], the incomplete relaxation of tidal stresses could play a role for stress buildup over several tidal cycles. Similar to the tide-induced seismicity of the Moon, episodic stress release accompanied by localized tectonic quakes may occur where a certain threshold stress limit value is exceeded.

Recent laboratory experiments in the low-temperature range below $220 \mathrm{~K}$ indicate that the resistence of polycrystaline water ice to tensile failure is strongly dependent on temperature, composition, grain size, and porosity [Litwin et al., 2012]. For consolidated pure ice and ice contaminated by solid impurities, tensile strength is reported to increase by a factor of a few times the commonly used value of $1 \mathrm{MPa}$, which could impede tide-induced tectonism under Titan surface conditions. However, crustal porosity and the presence of near-surface liquids would considerably reduce the ice resistence to fracture. Furthermore, these authors suggest that fracture toughness is more important than tensile strength in the event of low strain rates where fracture propagation rather than fracture initiation is the strength-limiting factor. It is therefore conceivable that a porous ice crust soaked with liquids and subject to tide-induced surface deformation would be conducive to the formation of zones of weakness near strongly tidally flexed areas as shown in Figure 7. The possible existence of crustal zones of weakness on Titan may cause episodic cryovolcanic activity induced by positive buoyancy through exsolution of volatiles upon decompression, and the subsequent ascent along fluid-filled fractures in analogy to dikes [Lopes et al., 2013]. Another mechanism to promote localized cryovolcanism might be shear heating by tide-induced strike-slip fault motion as suggested by Nimmo et al. [2007] to explain the heat and vapor production within the tiger-stripe regions near the south pole of Enceladus.

Equally to the leading hemisphere, two near-equatorial zones of strong tidal flexure and stress concentration are present on the trailing hemisphere. The apparent absence of cryovolcanic candidate features on the trailing hemisphere could be caused by the current observational bias toward the leading hemisphere. This is indicated in a recent multispectral map of Cassini VIMS and RADAR/SARtopo and altimetry data [Lorenz et al., 2013] that is based on extrapolation from the still relatively scarce data basis with several large gaps to be filled by future Cassini observations. Alternatively, the apparent hemispheric asymmetry of tectonic-like and volcanic-like features could be linked to erosional and depositional processes since Titan's surface is subject to intense resurfacing. The global distribution and characteristics of fluvial erosion on Titan indeed indicates seasonal climatic asymmetries between both hemispheres [Langhans et al., 2012]. Our findings further reveal that future Cassini observations of Titan's surface should focus on the tidally flexed regions in the trailing hemisphere and the polar areas that are more conducive to strike-slip motions. It must be expected that these regions could bear additional marks of the satellite's endogenic activity.

Titan is a dynamic satellite at present, as evidenced by the recent albedo changes observed in the Sotra Patera region and Tui Regio and the extensive surface changes spanning more than $500,000 \mathrm{~km}^{2}$ in the wake of a seasonal storm [Turtle et al., 2011]. Dynamic activity is thought to be conducive to habitable conditions on a planetary body as it allows the recycling of minerals and potential nutrients and provides localized energy sources by warm upwelling material. In a habitable environment, not only polymeric chemistry but also a fluid and semistable environment have to be present, as well as an energy source [Schulze-Makuch and Irwin, 2008]. Here we show that tidal forces are a constant and significant source of internal deformation on Titan. Furthermore, our model calculations suggest comparatively low ocean ammonia contents of less than $5 \mathrm{wt} \%$ and ocean temperatures in excess of $255 \mathrm{~K}$, i.e., higher than previously thought, thereby substantially increasing Titan's potential for habitable locations.

When addressing Titan's habitability, understanding its interior structure is of critical importance. In this study, we have adopted new laboratory data for the parameterization of the water-ammonia $\left(\mathrm{H}_{2} \mathrm{O}-\mathrm{NH}_{3}\right)$ phase diagram [Choukroun and Grasset, 2007, 2010] to determine the sizes of Titan's bulk reservoirs (crust, 
ocean, and deep interior) by assuming an isothermal subsurface ocean. It is important to remember that the thicknesses of the outer ice shell and of the subsurface ocean are linked to each other through the pressure-temperature phase relationships (phase diagram) of the water-ammonia system. Therefore, higher ocean temperatures yield larger ocean thicknesses and thinner ice shells and vice versa. For reasonable amounts of $\mathrm{NH}_{3}(<25 \mathrm{wt} \%)$, the ocean temperatures of successful structural models of Titan's interior are dependent on the ammonia concentration in the ocean. Smaller ammonia concentrations lead to warmer subsurface oceans and vice versa. A thinner crust would clearly be more conducive to putative life, because it could result in frequent cryovolcanism and upwelling of ammonia-water pulses near or onto the surface. Evidence for cryovolcanism was observed previously [Sotin et al., 2005; Lopes et al., 2007; Wall et al., 2009]. The diurnal tidal stresses as modeled for Titan could be large enough to result in geologic surface features: Liquid water-ammonia outbursts on the surface of Titan would clearly be a sign of a dynamic planetary body and may also provide suitable environmental niches for life, at least on a temporary basis. As a first step, our results indicate that one should look for such manifestations at the surface to bring additional evidence for the presence of the liquid water ocean.

Our modeling results also provide some constraints on the thickness of the water-ammonia ocean. For our reference model, we obtain a large ocean of about $180 \mathrm{~km}$ thickness, which would provide a huge reservoir of liquid water and ammonia. However, the ocean would be sandwiched between two layers of ice (Figure $4 \mathrm{a}$ ), and needed inorganic ions, which play a central role in Earth biology including redox chemistry $(\mathrm{Fe}, \mathrm{Cu}, \mathrm{Mn}, \mathrm{Co}, \mathrm{Mo}, \mathrm{Se}, \mathrm{S})$, acid-base catalysis ( $\mathrm{Zn}, \mathrm{Ni})$, transmission and storage of energy and information $(\mathrm{S}, \mathrm{B}, \mathrm{Si})$, and cell structure and homeostasis $(\mathrm{Ca}, \mathrm{Na}, \mathrm{K})$, may be hard to come by [e.g., Fortes, 2000]. If the ammonia-water solvent were in direct contact with the rocky core, as some models shown in Figure 2 suggest, hydrothermal vent communities as observed on Earth and modeled for Europa [e.g., Irwin and Schulze-Makuch, 2003] may represent a feasible possibility for Titan's subsurface.

Our findings for a large, warm subsurface ocean with possibly a thin crust above enhance the habitability and astrobiological potential of Titan, but even more make it a special target for future exploration as an object with unique properties in our solar system.

\section{Appendix A: Hydrostaticity and Spin Pole Orientation}

The ratio between the degree- 2 gravity coefficients $C_{2,2}$ and $J_{2}$ of a synchronously rotating satellite $(p=1)$ in hydrostatic equilibrium can be related to the spin and orbit parameters without a priori assumptions about the inertia tensor [Correia and Rodríguez, 2013]:

$$
\frac{C_{2,2}}{J_{2}}=\frac{3 H(p, e) \cos ^{4}(v / 2)}{(2 p)^{2}+\left(6-9 \sin ^{2} v\right)\left(1-e^{2}\right)^{-3 / 2}},
$$

where $v$ is the obliquity of the spin axis relative to the orbit pole, $e$ is orbital eccentricity, and $H(1, e)=$ $1-\frac{5}{2} e^{2}+\frac{13}{16} e^{4}$. Whereas $v$ was determined from Cassini RADAR data [Stiles et al., 2008, 2010], $J_{2}$ and $C_{2,2}$ were independently derived from Doppler radio science data collected during close encounters using suitable flyby geometries [less et al., 2010]. Insertion of the observational values collected in Table 1 on both sides of equation (A1) indicates that these observations are in excellent agreement with the assumption of hydrostaticity given by the theoretical prediction of $3 / 10$.

If Titan occupies a Cassini spin state, its spin axis and orbit normal precess at a uniform rate and remain coplanar with the normal of the invariable plane such that the magnitude of the angular distance between Titan's spin and orbit poles could impose additional constraints on Titan's interior structure [Bills and Nimmo, 2008, 2011; Baland et al., 2011]. In the event of coplanar precession, the spin obliquity $v$ and orbit inclination $i$ satisfy the Cassini condition [Peale, 1969, 1977]:

$$
(\alpha \cos v+\beta) \sin v=\sin (i-v)=\sin i \cos v-\sin v \cos i,
$$

which is equivalent to

$$
(\cos i+\alpha \cos v+\beta) \sin v=\sin i \cos v
$$

or

$$
\tan v=\frac{\sin i}{\cos i+\alpha \cos v+\beta}=\frac{\tan i}{1+\frac{\alpha \cos v+\beta}{\cos i}}
$$


The parameters $\alpha$ and $\beta$ are given by [Peale, 1969, 1977]

$$
\alpha=\frac{3}{2} \frac{\omega}{c \dot{\Omega}}\left(J_{2}+2 C_{2,2}\right)\left(1+\frac{3}{2} e^{2}\right)
$$

and

$$
\beta=\frac{3}{2} \frac{\omega}{c \dot{\Omega}} C_{2,2}\left[1-\frac{5}{2} e^{2}-\left(1+\frac{11}{2} e^{2}\right) \cos v\right],
$$

where $\omega$ is the mean orbital motion, $\dot{\Omega}$ is the node precession rate, and $c$ is the dimensionless moment-of-inertia (Mol) factor of the outer ice shell. In the limit of small inclination $i$ and obliquity $v$, $\cos i \sim \cos v \sim 1$, and equation (A4) simplifies to

$$
\tan v=\frac{\tan i}{1+\alpha+\beta}
$$

From insertion of equations (A5) and (A6) in equation (A7), we obtain the ratio between both angles:

$$
\frac{i}{V}=1+\frac{3}{2} \frac{\omega}{c \dot{\Omega}}\left[\left(1+\frac{3}{2} e^{2}\right)\left(J_{2}+2 C_{2,2}\right)-8 e^{2} C_{2,2}\right],
$$

which is slightly different from equation (26) reported in Bills and Nimmo [2008]. If quadratic terms in $e$ are neglected and the hydrostatic ratio $C_{2,2} / J_{2}=3 / 10$ is incorporated from equation (A1), we finally obtain

$$
\frac{i}{v}=1+8 \frac{\omega}{c \dot{\Omega}} C_{2,2}
$$

Upon insertion of the rate ratio $\omega / \dot{\Omega}=-1.391 \times 10^{4}$, the orbit inclination $i=0.28^{\circ}$ [Bills and Nimmo, 2008], and the degree-2 gravity coefficient $C_{2,2}=10.02 \times 10^{-6}$ [less et al., 2010], principal bounds on Titan's obliquity ranging between $v=-0.16^{\circ}$ in the homogeneous case (Mol factor $c=2 / 5$ ) and $v=-0.42^{\circ}$ in the thin-shell case (Mol factor $c=2 / 3$ ) are obtained. The corresponding precession period of the spin pole, $\Gamma$, is given by

$$
\Gamma=\frac{2 \pi}{\dot{\Omega}(\alpha+\beta)}=P_{n}\left(\frac{i}{v}-1\right)
$$

where $P_{n}=2 \pi / \dot{\Omega}$ denotes the nodal regression period listed in Table 1 and may range from 220 years (Mol factor $c=2 / 5$ ) to 365 years (Mol factor $c=2 / 3$ ). Bills and Nimmo $[2008,2011]$ inferred that Titan's outer ice shell is likely decoupled from the deep interior by an ocean since the radar-observed obliquity of $-0.32^{\circ}$ [Stiles et al., 2008, 2010; Baland et al., 2011] falls within the obliquity range defined by the limiting model cases.

The Mol factor of a spherical shell is given by

$$
c=\frac{\delta C}{\delta M R_{s}^{2}}=\frac{2}{5} \frac{1-\left(\frac{R_{b}}{R_{s}}\right)^{5}}{1-\left(\frac{R_{b}}{R_{s}}\right)^{3}},
$$

where $R_{b}$ is the radial distance of the interface between the outer ice shell and the subsurface ocean, $R_{s}$ is the surface radius, and $\delta C$ and $\delta M$ are shell moment of inertia and mass, respectively. From substitution of the shell thickness $d_{c}=R_{s}-R_{b}$ and second truncation of the resultant binomial series approximation in equation (A11), the following thin-shell approximation is obtained:

$$
c=\frac{\delta C}{\delta M R_{s}^{2}}=\frac{2}{3}\left[1-\frac{d_{c}}{R_{s}}+\frac{2}{3}\left(\frac{d_{c}}{R_{s}}\right)^{2}\right] .
$$

According to equations (A9) and (A10), Titan's radar-observed obliquity corresponds to a shell Mol factor of $c=0.595$ and a spin-pole precession period of $\Gamma=328$ years, respectively. Based on the assumption that dynamic and gravitational coupling effects can be neglected in this initial analysis, equation (A12) yields a shell thickness $d_{c}$ in agreement with Titan's rotational state on the order of $300 \mathrm{~km}$, still at odds with the interpretation of the low-degree gravitational field [less et al., 2010] and long-wavelength topography data [Zebker et al., 2009]. 
Table B1. Modeling Parameters of the Silicate Core ${ }^{a}$

\begin{tabular}{|c|c|c|c|}
\hline Parameter & Symbol & Units & Value \\
\hline \multicolumn{4}{|c|}{ Serpentinite } \\
\hline Reference density ${ }^{d}$ & $\rho_{0}$ & $\mathrm{~g} \mathrm{~cm}^{-3}$ & 2.558 \\
\hline Reference bulk modulus ${ }^{d}$ & $K_{0}$ & $\mathrm{GPa}$ & $67.27-0.01 T$ \\
\hline Pressure derivative of the bulk modulus ${ }^{d}$ & $K^{\prime}$ & - & 4.0 \\
\hline Reference shear modulus $^{\mathrm{e}}$ & $\mu_{0}$ & GPa & 45.04 \\
\hline Pressure derivative of the shear modulus ${ }^{\mathrm{e}}$ & $\mu^{\prime}$ & - & 0.78 \\
\hline Thermal expansivity $^{d}$ & $\alpha$ & $\mathrm{K}^{-1}$ & $2.00 \times 10^{-5}$ \\
\hline Thermal conductivity & $k_{c}$ & $\mathrm{~W} \mathrm{~m}^{-1} \mathrm{~K}^{-1}$ & $-\mathrm{b}$ \\
\hline Specific heat capacity ${ }^{f}$ & $c_{p}$ & $\mathrm{~J} \mathrm{~kg}^{-1} \mathrm{~K}^{-1}$ & $\begin{array}{c}1987-1.39 T^{-0.5}-3.22 \times 10^{-3} T^{-2} \\
+4.204 \times 10^{-4} T^{-3}\end{array}$ \\
\hline \multicolumn{4}{|c|}{ Brucite } \\
\hline Reference densityg & $\rho_{0}$ & $\mathrm{~g} \mathrm{~cm}^{-3}$ & $2.403^{c}$ \\
\hline Reference bulk modulus ${ }^{9}$ & $K_{0}$ & $\mathrm{GPa}$ & $50.6-0.0114 T^{c}$ \\
\hline Pressure derivative of the bulk modulus ${ }^{g}$ & $K^{\prime}$ & - & $4.7^{c}$ \\
\hline Reference shear modulus ${ }^{\mathrm{h}}$ & $\mu_{0}$ & GPa & $35.5^{c}$ \\
\hline Pressure derivative of the shear modulus ${ }^{\mathrm{h}}$ & $\mu^{\prime}$ & - & $2.4^{c}$ \\
\hline Thermal expansivity ${ }^{f}$ & $\alpha$ & $\mathrm{K}^{-1}$ & $5.00 \times 10^{-5}$ \\
\hline Thermal conductivity & $k_{c}$ & 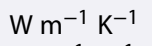 & $-\mathrm{b}$ \\
\hline Specific heat capacity ${ }^{f}$ & $C_{p}$ & $\mathrm{~J} \mathrm{~kg}^{-1} \mathrm{~K}^{-1}$ & $\begin{array}{c}2346.4-0.9210 T^{-0.5}-7.4793 \times 10^{-3} T^{-2} \\
+9.4769 \times 10^{-5} T^{-3}\end{array}$ \\
\hline \multicolumn{4}{|c|}{ Olivine } \\
\hline Reference density ${ }^{d}$ & $\rho_{0}$ & $\mathrm{~g} \mathrm{~cm}^{-3}$ & 3.343 \\
\hline Reference bulk modulus $^{d}$ & $K_{0}$ & $\mathrm{GPa}$ & $131.1-0.0223 T$ \\
\hline Pressure derivative of the bulk modulus ${ }^{d}$ & $K^{\prime}$ & - & 3.8 \\
\hline Reference shear modulus ${ }^{i}$ & $\mu_{0}$ & $\mathrm{GPa}$ & $82^{c}$ \\
\hline Pressure derivative of the shear modulus ${ }^{\mathrm{i}}$ & $\mu^{\prime}$ & - & $0.84^{c}$ \\
\hline Thermal expansivity ${ }^{d}$ & $\alpha$ & $\mathrm{K}^{-1}$ & $2.66 \times 10^{-5}$ \\
\hline Thermal conductivity & $k_{c}$ & 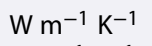 & $-{ }^{\mathrm{b}}$ \\
\hline Specific heat capacity ${ }^{f}$ & $c_{p}$ & $\mathrm{~J} \mathrm{~kg}^{-1} \mathrm{~K}^{-1}$ & $1696.2-1.4225 T^{-0.5}-8.2620 \times 10^{-6} T^{-3}$ \\
\hline $\begin{array}{l}\text { aThe olivine data are given for comparis } \\
{ }^{b} \text { Calculated using a thermal diffusivity } \\
{ }^{c} \text { Value refitted to the appropriate equat } \\
{ }^{d} \text { Fortes [2012, and references therein]. } \\
{ }^{\mathrm{e}} \text { Mookherjee and Stixrude [2009], Mookh } \\
\mathrm{f}_{\text {Berman and Brown [1985]. }} \\
{ }^{\mathrm{g} X i a} \text { et al. [1998]. } \\
\text { h Jiang et al. [2006]. } \\
{ }^{\mathrm{i} S t i x r u d e} \text { and Lithgow-Bertelloni [2011]. }\end{array}$ & $\begin{array}{l}10^{-6} \text { for } \\
\text { of state. }\end{array}$ & $\begin{array}{l}\text { ch mineral, re } \\
\text { ani [2011]. }\end{array}$ & ectively. \\
\hline
\end{tabular}

\section{Appendix B: The Hydrated Silicate Core}

For serpentine $\left(\mathrm{Mg}_{48} \mathrm{Si}_{34} \mathrm{O}_{85}(\mathrm{OH})_{62}\right)$ and brucite $\left(\mathrm{Mg}(\mathrm{OH})_{2}\right)$ a Murnaghan equation of state is used to calculate the density as a function of depth. The corresponding parameters for this equation of state are summarized in Table B1.

Internal heat generation is considered only due to the decay of long-lived radiogenic nuclides in the rocky core, for which we assume a present-day specific heat production rate $\epsilon$ of $5.0 \times 10^{-12} \mathrm{~W} \mathrm{~kg}^{-1}$, implying a chondritic bulk composition [e.g., Spohn and Schubert, 2003]. Additional heat sources are not taken into account, e.g., the dissipation of tidal energy or latent heat release due to crystallization processes.

To assess the thermal structure of the rocky core, we need to calculate the thermal expansivity $\alpha$, the thermal conductivity $k_{c}$, and the specific heat capacity $C_{p}$ for the constituent minerals, respectively. For this purpose, we adopt experimentally obtained relationships from various sources. The corresponding values are collected in Table B1.

The viscosity of the rocky core is adjusted such that the central temperature will not exceed a critical threshold temperature of about $900 \mathrm{~K}$ for silicate dehydration [e.g., Perrillat et al., 2005; Castillo-Rogez and Lunine, 2010]. That resulting viscosity is similarly large than the present-day value obtained by Grindrod et al. [2008] using a thermal evolution model with variable viscosity. 
Table C1. Modeling Parameters of the High-Pressure Water-Ice Shell

\begin{tabular}{lccc} 
Parameter & Symbol & Units & Value \\
\hline Reference density $^{\mathrm{a}}$ & $\rho_{0}$ & $\mathrm{~g} \mathrm{~cm}^{-3}$ & $1.3268 \exp \left(-1.495 \times 10^{-7} \mathrm{~T}^{2.2796}\right)$ \\
Reference bulk modulus $^{\mathrm{a}}$ & $K_{0}$ & $\mathrm{GPa}$ & $17.82-0.0385 T+3.625 \times 10^{-5} \mathrm{~T}^{2}$ \\
Pressure derivative of the bulk modulus $^{\mathrm{a}}$ & $K^{\prime}$ & - & 5.40 \\
Thermal expansivity $^{\mathrm{b}}$ & $\alpha$ & $\mathrm{K}^{-1}$ & $3.506 \times 10^{-7} T+3.783 \times 10^{-6}$ \\
Thermal conductivity $^{\mathrm{b}}$ & $k_{c}$ & $\mathrm{~W} \mathrm{~m}^{-1} \mathrm{~K}^{-1}$ & $-2.757 \times 10^{-7} T^{3}+1.969 \times 10^{-4} T^{2}$ \\
& & & $-0.05119 T+6.557$ \\
Specific heat capacity & $C_{P}$ & $\mathrm{~J} \mathrm{~kg}^{-1} \mathrm{~K}^{-1}$ & $-0.0366 T^{2}+26.315 T-1896.8$ \\
\hline
\end{tabular}

${ }^{\mathrm{a}}$ Fortes [2012, and references therein].

${ }^{\mathrm{b}}$ Grindrod et al. [2008].

\section{Appendix C: The High-Pressure Water-Ice Shell}

We use Murnaghan's integrated linear equation of state to determine the local density in the high-pressure water-ice shell. Table $\mathrm{C} 1$ lists the parameters used for the appropriate equation of state.

To assess the thermal structure of the high-pressure water-ice shell, we need to calculate thermal expansivity $\alpha$, thermal conductivity $k_{c}$, and specific heat capacity $C_{p}$. For this purpose, we adopt the relationships given by Grindrod et al. [2008] as derived from fitting experimental water-ice VI data of various sources. The corresponding expressions are compiled in Table $\mathrm{C} 1$.

Furthermore, we assume a constant viscosity of $10^{16} \mathrm{~Pa}$, which is compliant with the viscosity range of $10^{14}$ to $10^{17}$ Pa s for water-ice VI suggested by Poirier et al. [1981] and slightly lower than the viscosity calculated by Grindrod et al. [2008], applying a melting temperature-scaled viscosity relationship.

\section{Appendix D: The Ocean-Ice System}

The used equation of state parameters for pure water and ammonia are listed in Table D1. These parameters represent a Murnaghan-type fit to experimentally obtained data, respectively. The depth-dependent density of a water-ammonia mixture can then be calculated following the approach described by Croft et al. [1988].

A central assumption of the presented model approach is that the temperature within the subsurface ocean is considered as isothermal and does not change with depth. This assumption is justified because of the strong convective flow that must be expected within the ocean. The ocean temperature depends on the prescribed ammonia concentration of the ocean, which has been varied between 0 and $25 \mathrm{wt} \%$.

Table D1. Modeling Parameters for the Subsurface $\mathrm{H}_{2} \mathrm{O}-\mathrm{NH}_{3}$ Ocean

\begin{tabular}{|c|c|c|c|}
\hline Parameter & Symbol & Units & Value \\
\hline \multicolumn{4}{|l|}{ Water (liquid) } \\
\hline Reference density ${ }^{b}$ & $\rho_{0}$ & $\mathrm{~g} \mathrm{~cm}^{-3}$ & 0.9991 \\
\hline Reference bulk modulus ${ }^{b}$ & $K_{0}$ & kbar & $-73.184+0.5910 T-9.139 \times 10^{-4} T^{2}$ \\
\hline Pressure derivative of the bulk modulus ${ }^{b}$ & $K^{\prime}$ & - & $39.999-0.2058 T+3.111 \times 10^{-4} T^{2}$ \\
\hline Thermal expansivityc & $\alpha$ & $\mathrm{K}^{-1}$ & $2.1 \times 10^{-4}$ \\
\hline Thermal conductivity ${ }^{c}$ & $k_{c}$ & $\mathrm{~W} \mathrm{~m}^{-1} \mathrm{~K}^{-1}$ & 0.566 \\
\hline Specific heat capacity ${ }^{d}$ & $C_{P}$ & $\mathrm{~J} \mathrm{~kg}^{-1} \mathrm{~K}^{-1}$ & 4200 \\
\hline \multicolumn{4}{|l|}{ Ammonia (liquid) } \\
\hline Reference density ${ }^{b}$ & $\rho_{0}$ & $\mathrm{~g} \mathrm{~cm}^{-3}$ & 0.6177 \\
\hline Reference bulk modulus ${ }^{b}$ & $K_{0}$ & kbar & $48.503 \exp \left(-1.0134 \times 10^{-3} T^{1.3067}\right)$ \\
\hline Pressure derivative of the bulk modulus ${ }^{b}$ & $K^{\prime}$ & - & $4.0858 \times 10^{16} T^{-6.6083}+4.1831$ \\
\hline Thermal expansivity & $\alpha$ & $\mathrm{K}^{-1}$ & $2.1 \times 10^{-4 a}$ \\
\hline Thermal conductivity & $k_{c}$ & $\mathrm{~W} \mathrm{~m}^{-1} \mathrm{~K}^{-1}$ & $0.566^{a}$ \\
\hline Specific heat capacity & $C_{p}$ & $\mathrm{~J} \mathrm{~kg}^{-1} \mathrm{~K}^{-1}$ & $4200^{a}$ \\
\hline
\end{tabular}

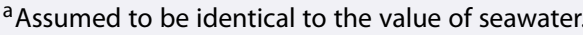

${ }^{\mathrm{b}}$ Croft et al. [1988].

${ }^{c}$ Hill [1962].

d Kirk and Stevenson [1987].
} 
Table D2. Equation of State Parameters for the Water-Ice and Methane-Hydrate Crust According to Helgerud et al. [2009] $]^{\mathrm{a}}$

\begin{tabular}{lccccc} 
Parameter & Symbol & Units & $A^{*}$ & $B^{*}$ & $C^{*}$ \\
\hline Water-ice (Ih) & & & & & \\
Density & $\rho$ & $\mathrm{g} \mathrm{cm}^{-3}$ & $-1.5035 \times 10^{-4}$ & $1.0594 \times 10^{-4}$ & 0.91673 \\
Bulk modulus & $K$ & $\mathrm{GPa}$ & $-1.48 \times 10^{-2}$ & $3.4 \times 10^{-3}$ & 9.07 \\
Shear modulus & $\mu$ & $\mathrm{GPa}$ & $-5.03 \times 10^{-3}$ & $3.0 \times 10^{-4}$ & 3.459 \\
Compressional wave speed & $V_{P}$ & $\mathrm{~m} \mathrm{~s}^{-1}$ & -2.67 & 0.2 & 3864 \\
Shear wave speed & $v_{S}$ & $\mathrm{~m} \mathrm{~s}^{-1}$ & -1.244 & -0.198 & 1942.4 \\
Methane hydrate (sl) & & & & & 0.92435 \\
Density & $\rho$ & $\mathrm{g} \mathrm{cm}^{-3}$ & $-2.3815 \times 10^{-4}$ & $1.1843 \times 10^{-4}$ & 0.39 \\
Bulk modulus & $K$ & $\mathrm{GPa}^{-3}$ & $-1.09 \times 10^{-2}$ & $3.8 \times 10^{-3}$ & 8.541 \\
Shear modulus & $\mu$ & $\mathrm{GPa}^{-3}$ & $-4.2 \times 10^{-3}$ & $9 \times 10^{-5}$ & 3766 \\
Compressional wave speed & $v_{P}$ & $\mathrm{~m} \mathrm{~s}^{-1}$ & -1.84 & 0.31 & 1957.0 \\
Shear wave speed & $v_{S}$ & $\mathrm{~m} \mathrm{~s}^{-1}$ & -0.892 & -0.100 & 3.100 \\
\hline
\end{tabular}

a Units for $A^{*}$ are the units of the corresponding parameter divided by ${ }^{\circ} \mathrm{C}$. Units for $B^{*}$ are the units of the corresponding parameter divided by MPa. Units for $C^{*}$ are the units of the corresponding parameter.

For the thermal expansivity $\alpha$, the thermal conductivity $k_{c}$, and the specific heat capacity $C_{p}$ of the water-ammonia system values, we use values determined for seawater (Table D1), implicitly assuming that the differences between the water-ammonia mixture and seawater are small.

To obtain the elastic moduli $K$ and $\mu$ of the outer ice shell, we use linear planar fits to laboratory data reported by Helgerud et al. [2009] and calculate the seismic velocities according to equations (10) and (11). Table D2 lists the corresponding fit parameters of both chemical end-members (water ice and methane hydrate), respectively. While the fit parameters $A^{*}, B^{*}$, and $C^{*}$ for both water-ice $\mathrm{Ih}$ and $\mathrm{s}$ methane are listed in Table D2, the corresponding thermal properties, i.e., thermal expansivity $\alpha$, thermal conductivity $k_{c}$, and specific heat capacity $C_{p}$, are summarized in Table D3.

The viscosity of the outer ice shell is assumed to be $10^{20} \mathrm{~Pa} \mathrm{~s}$, in agreement with the assumption that the ice shell is not convecting [Nimmo and Bills, 2010].

\section{Appendix E: Diurnal Tidal Stress}

Diurnal stress variations at Titan's surface due to body tides are attributed to the satellite's significant orbital eccentricity and obliquity. The diurnal tidal stress can be expressed in terms of shear $\left(\tau_{s}\right)$ and normal stress $\left(\sigma_{\mathrm{n}}\right)$, acting on an arbitrarily oriented surface element [e.g., Turcotte and Schubert, 2002; Smith-Konter and Pappalardo, 2008]:

$$
\sigma_{n}=\sigma_{\theta \theta} \cos ^{2} \gamma+\sigma_{\phi \phi} \sin ^{2} \gamma+\tau_{\theta \phi} \sin 2 \gamma
$$

Table D3. Modeling Parameters for the Water-Ice and Methane-Hydrate Crust

\begin{tabular}{|c|c|c|c|}
\hline Parameter & Symbol & Units & Value \\
\hline \multicolumn{4}{|l|}{ Water-ice (Ih) } \\
\hline Thermal expansivity ${ }^{\mathrm{a}}$ & $\alpha$ & $\mathrm{K}^{-1}$ & $6.24 \times 10^{-7} T$ \\
\hline Thermal conductivity ${ }^{b}$ & $k_{c}$ & $W m^{-1} K^{-1}$ & $0.4685+488 T^{-1}$ \\
\hline Specific heat capacity ${ }^{b}$ & $C_{p}$ & $\mathrm{~J} \mathrm{~kg}^{-1} \mathrm{~K}^{-1}$ & $7.037 T+185$ \\
\hline \multicolumn{4}{|l|}{ Methane hydrate (sl) } \\
\hline Thermal expansivityc & $\alpha$ & $\mathrm{K}^{-1}$ & $2.09 \times 10^{-9} T+3.7 \times 10^{-8}$ \\
\hline Thermal conductivityc & $k_{c}$ & 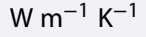 & $0.498-2.30 T^{-1}+4.708 T^{-2}-3.718 T^{-3}$ \\
\hline Specific heat capacity ${ }^{c}$ & $C_{p}$ & $\mathrm{~J} \mathrm{~kg}^{-1} \mathrm{~K}^{-1}$ & $4.971 \times 10^{-5} T^{3}-0.0289 T^{2}+11.66 T+55.92$ \\
\hline
\end{tabular}

${ }^{\text {a } K i r k}$ and Stevenson [1987].

${ }^{\mathrm{b}}$ Hillier and Squyres [1991].

'Grindrod et al. [2008]. 
and

$$
\tau_{s}=\frac{1}{2}\left(\sigma_{\phi \phi}-\sigma_{\theta \theta}\right) \sin 2 \gamma+\tau_{\theta \phi} \cos 2 \gamma
$$

where the inclination angle $\gamma$ is measured relative to the longitudinal direction [see Nimmo et al., 2007] (supporting information). In general, the stresses are specified by the nonzero components of the diurnal stress tensor in latitudinal $\left(\sigma_{\theta \theta}\right)$, longitudinal $\left(\sigma_{\phi \phi}\right)$, and cross directions $\left(\tau_{\theta \phi}=\tau_{\phi \theta}\right)$ and further related to the time-variable tidal potential $\Phi_{e}$ at the satellite's surface [Wahr et al., 2009]:

$$
\begin{gathered}
\sigma_{\theta \theta}=\frac{2 \mu}{g_{s} R_{s}(\lambda+2 \mu)}\left\{h_{2}(3 \lambda+2 \mu) \Phi_{e}+I_{2}\left[\frac{\lambda}{\sin ^{2} \theta} \frac{\partial^{2} \Phi_{e}}{\partial \phi^{2}}+\lambda \cot \theta \frac{\partial \Phi_{e}}{\partial \theta}+2(\lambda+\mu) \frac{\partial^{2} \Phi_{e}}{\partial \theta^{2}}\right]\right\} \\
\sigma_{\phi \phi}=\frac{2 \mu}{g_{s} R_{s}(\lambda+2 \mu)}\left\{h_{2}(3 \lambda+2 \mu) \Phi_{e}+I_{2}\left[\frac{2(\lambda+\mu)}{\sin ^{2} \theta} \frac{\partial^{2} \Phi_{e}}{\partial \phi^{2}}+2(\lambda+\mu) \cot \theta \frac{\partial \Phi_{e}}{\partial \theta}+\lambda \frac{\partial^{2} \Phi_{e}}{\partial \theta^{2}}\right]\right\} \\
\tau_{\theta \phi}=\tau_{\phi \theta}=\frac{2 \mu I_{2}}{g_{s} R_{s} \sin \theta}\left(\frac{\partial^{2} \Phi_{e}}{\partial \theta \partial \phi}-\cot \theta \frac{\partial \Phi_{e}}{\partial \theta}\right),
\end{gathered}
$$

where $\lambda=K-2 / 3 \mu=2 \mu \nu /(1-2 v)$ is Lamé's first parameter, $\mu$ is shear modulus, $v$ is Poisson's ratio, $h_{2}$ is radial displacement Love number, and $I_{2}$ is tangential displacement Shida number. The Poisson ratio of the outer ice shell is held fixed at $v=1 / 3$ for ice Ih [Helgerud et al., 2009], corresponding to the model case $\lambda=2 \mu$.

The diurnal stress tensor can be expressed in terms of orthogonal principal stresses $\sigma_{\max }$ and $\sigma_{\min }$ such that shear stresses vanish [e.g., Turcotte and Schubert, 2002]

$$
\sigma_{\max , \min }=\frac{\sigma_{\theta \theta}+\sigma_{\phi \phi}}{2} \pm\left[\left(\frac{\sigma_{\theta \theta}-\sigma_{\phi \phi}}{2}\right)^{2}+\tau_{\theta \phi}^{2}\right]^{1 / 2}
$$

and the orientation angle $\gamma_{\mathrm{P}}$ of the principal stress axis given by

$$
\gamma_{P}=\frac{1}{2} \arctan \left(\frac{2 \tau_{\theta \phi}}{\sigma_{\theta \theta}-\sigma_{\phi \phi}}\right) .
$$

Since we are interested in global amplitude patterns of diurnal tidal stresses, we calculate the maximum tensile (areal) stress [Zürn and Wilhelm, 1984]

$$
\sigma_{\text {areal }}=\frac{1}{2}\left(\sigma_{\max }+\sigma_{\min }\right)=\frac{1}{2}\left(\sigma_{\theta \theta}+\sigma_{\phi \phi}\right)
$$

Acknowledgments

The Editor, Associate Editor and reviewers are thanked for constructive remarks helping to improve the manuscript. We acknowledge fruitful discussions with Nicola Tosi, Ana-Catalina Plesa, and Eleni Kalogirou. This research has been partly supported by the Helmholtz Association through the research alliances "Planetary Evolution and Life" and "Robotic Exploration of Extreme Environments (ROBEX)." A. Solomonidou has been cofinanced by the European Union (European Social Fund ESF) and Greek national funds through the Operational Program "Education and Lifelong Learning" of the National Strategic Reference Framework-Research Funding Program: Heracleitus II. Investing in knowledge society through the European Social Fund. The revision of this paper was supported by the JPL, Caltech, under a contract with NASA. and the maximum shear stress $\left(\gamma_{\mathrm{P}}=\pi / 4\right)$

$$
\tau_{\text {shear }}=\frac{1}{2}\left(\sigma_{\max }-\sigma_{\min }\right)=\left[\left(\frac{\sigma_{\theta \theta}-\sigma_{\phi \phi}}{2}\right)^{2}+\tau_{\theta \phi}^{2}\right]^{1 / 2}
$$

at Titan's surface, whereas the maximum diurnal tidal stress $\bar{\sigma}_{\text {tide }}$ is obtained from the second invariant of the stress tensor [e.g., Gerya, 2010]

$$
\bar{\sigma}_{\text {tide }}=\left[\frac{1}{2}\left(\sigma_{\theta \theta}^{2}+\sigma_{\phi \phi}^{2}+2 \tau_{\theta \phi}^{2}\right)\right]^{1 / 2}
$$

\section{References}

Abe, Y. (1995), Basic equations for the evolution of partially molten mantel and core, The Earth's Central Part: Its Structure and Dynamics, pp. 215-230, Terra Scientific Publishing Company, Tokyo.

Abe, Y. (1997), Thermal and chemical evolution of the terrestrial magma ocean, Phys. Earth Planet. Inter., 100, $27-39$.

Atreya, S., E. Adams, H. Niemann, J. Demick-Montelara, T. Owen, M. Fulchignoni, F. Ferri, and E. Wilson (2006), Titan's methane cycle, Planet. Space Sci., 54, 1177-1187.

Baland, R.-M., T. van Hoolst, M. Yseboodt, and Ö. Karatekin (2011), Titan's obliquity as evidence of a subsurface ocean?, Astron. Astrophys., 530, A141-A147.

Barnes, J. W., et al. (2006), Cassini observations of flow-like features in western Tui Regio, Titan, Geophys. Res. Lett., 33, L16204, doi:10.1029/2006GL026843. 
Barnes, J. W., et al. (2007), Near-infrared spectral mapping of Titan's mountains and channels, J. Geophys. Res., 112, E11006, doi:10.1029/2007JE002932.

Barnes, J. W., et al. (2011), Organic sedimentary deposits in Titan's dry lakebeds: Probable evaporite, Icarus, 216, 136-140.

Berman, R. G., and T. H. Brown (1985), Heat capacity of minerals in the system $\mathrm{Na}_{2} \mathrm{O}-\mathrm{K}_{2} \mathrm{O}-\mathrm{CaO}-\mathrm{MgO}-\mathrm{FeO}-\mathrm{Fe}_{2} \mathrm{O}_{3}-\mathrm{Al}_{2} \mathrm{O}_{3}-\mathrm{SiO}_{2}-\mathrm{TiO}_{2}-\mathrm{H}_{2}$

$\mathrm{O}-\mathrm{CO}_{2}$ : Representation, estimation, and high temperature extrapolation, Contrib. Mineral. Petrol., 89, 168-183.

Beuthe, M. (2013), Spatial patterns of tidal heating, Icarus, 223, 308-329.

Bills, B. G., and F. Nimmo (2008), Forced obliquity and moments of inertia of Titan, Icarus, 196, 293-297.

Bills, B. G., and F. Nimmo (2011), Rotational dynamics and internal structure of Titan, Icarus, 214, 351-355.

Burr, D. M., R. E. Jacobsen, D. L. Roth, C. B. Phillips, K. L. Mitchell, and D. Viola (2009), Fluvial network analysis on Titan: Evidence for subsurface structures and west-to-east wind flow, southwestern Xanadu, Geophys. Res. Lett., 36, L22203, doi:10.1029/2009GL040909.

Castillo-Rogez, J. C., and J. I. Lunine (2010), Evolution of Titan's rocky core constrained by Cassini observations, Geophys. Res. Lett., 37, L20205, doi:10.1029/2010GL044398.

Cheng, C. H., and M. N. Toksöz (1978), Tidal stresses in the Moon, J. Geophys. Res., 83, 845-853.

Choukroun, M., and O. Grasset (2007), Thermodynamic model for water and high-pressure ices up to $2.2 \mathrm{GPa}$ and down to the metastable domain, J. Chem. Phys., 127(124), 506.

Choukroun, M., and O. Grasset (2010), Thermodynamic data and modeling of the water and ammonia-water phase diagrams up to 2.2 GPa for planetary geophysics, J. Chem. Phys., 133(144), 502.

Cook, C., J. W. Barnes, S. A. Kattenhorn, J. Radebaugh, T. Hurford, and B. Stiles (2013), Evidence for global contraction on Titan from patterns of tectonism, in 44th Lunar and Planetary Science Conference, Held March 18-22, 2013 in The Woodlands, Houston, Texas. LPI Contribution No. 1719, pp. 2509.

Correia, A. C. M., and A. Rodríguez (2013), On the equilibrium figure of close-in planets and satellites, Astrophys. J., 767, 128-133.

Coustenis, A., and M. Hirtzig (2009), Cassini-Huygens results on Titan's surface, Res. Astron. Astrophys., 9, 249-268.

Croft, S. K., J. I. Lunine, and J. Kargel (1988), Equation of state of ammonia-water liquid: Derivation and planetological applications, Icarus, $73,279-293$.

Fortes, A. D. (2000), Exobiological implications of a possible ammonia-water ocean inside Titan, Icarus, 146, 444-452.

Fortes, A. D. (2012), Titan's internal structure and the evolutionary consequences, Planet. Space Sci., 60, 10-17.

Fortes, A. D., P. M. Grindrod, S. K. Trickett, and L. Vočadlo (2007), Ammonium sulfate on Titan: Possible origin and role in cryovolcanism, Icarus, 188, 139-153.

Fulchignoni, M., et al. (2005), In situ measurements of the physical characteristics of Titan's environment, Nature, 438, 785-791.

Gagnon, R. E., H. Kiefte, M. J. Clouter, and E. Whalley (1990), Acoustic velocities and density of polycrystalline ice Ih, II, III, V, and VI by Brillouin spectroscopy, J. Chem. Phys., 92, 1910-1914.

Gao, P., and D. J. Stevenson (2013), Nonhydrostatic effects and the determination of icy satellites' moment of inertia, Icarus, 226, $1185-1191$.

Gerya, T. (2010), Introduction to Numerical Geodynamic Modelling, Cambridge Univ. Press, Cambridge.

Grasset, O., C. Sotin, and F. Deschamps (2000), On the internal structure and dynamics of Titan, Planet. Spa. Sci., 48, 617-636.

Grasset, O., M. Blanc, A. Coustenis, W. Durham, H. Hussmann, R. Pappalardo, and D. Turrini (2010), Satellites of the Outer Solar System: Exchange Processes Involving the Interiors, Springer, New York.

Griffith, C. A., T. Owen, and R. Wagener (1991), Titan's surface and troposphere, investigated with ground-based, near-infrared observations, Icarus, 93, 362-378.

Grindrod, P. M., A. D. Fortes, F. Nimmo, D. L. Feltham, J. P. Brodholt, and L. Vočadlo (2008), The long-term stability of a possible aqueous ammonium sulfate ocean inside Titan, Icarus, 197, 137-151.

Guinan, M., and D. Steinberg (1975), A simple approach to extrapolating measured polycrystalline shear moduli to very high pressure, J. Phys. Chem. Solids, 36, 829.

Helgerud, M. B., W. F. Waite, S. H. Kirby, and A. Nur (2009), Elastic wave speeds and moduli in polycristalline ice Ih, sl methane hydrate, and sll methane-ethane hydrate, J. Geophys. Res., 114, B02212, doi:10.1029/2008JB006132.

Hill, M. N. (1962), The Sea, Interscience Publishers.

Hillier, J., and S. W. Squyres (1991), Thermal stress tectonics on the satellites of Saturn and Uranus, J. Geophys. Res., 96, 15,665-15,674. Hirtzig, M., et al. (2013), Titan's surface and atmosphere from Cassini/VIMS data with updated methane opacity, Icarus, 226, 470-486.

Hurford, T. A., A. R. Sarid, R. Greenberg, and B. G. Bills (2009), The influence of obliquity on europan cycloid formation, Icarus, 202, 197-215.

Hussmann, H., F. Sohl, and J. Oberst (2011), Measuring tidal deformations at Europa's surface, Adv. Space Res., 48, 718-724.

less, L., N. J. Rappaport, R. A. Jacobson, P. Racioppa, D. J. Stevenson, P. Tortora, J. W. Armstrong, and S. W. Asmar (2010), Gravity field, shape, and moment of inertia of Titan, Science, 327, 1367-1369.

less, L., R. A. Jacobson, M. Ducci, D. J. Stevenson, J. I. Lunine, J. W. Armstrong, S. W. Asmar, P. Racioppa, N. Rappaport, and P. Tortora (2012), The tides of Titan, Science, 337, 457-459.

Irwin, L. N., and D. Schulze-Makuch (2003), Strategy for modeling putative ecosystems on Europa, Astrobiology, 3, 813-821.

Jara-Orué, H. M., and B. L. A. Vermeersen (2011), Effects of low-viscous layers and a non-zero obliquity on surface stresses induced by diurnal tides and non-synchronous rotation: The case of Europa, Icarus, 215, 417-438.

Jaumann, R., et al. (2008), Fluvial erosion and post erosional processes on Titan, Icarus, 197, 526-638.

Jaumann, R., C. N. Roger, F. Nimmo, A. R. Hendrix, B. J. Buratti, T. Denk, J. M. Moore, P. M. Schenk, S. J. Ostro, and R. Srama (2009), Icy satellites: Geological evolution and surface processes, Saturn From Cassini-Huygens, pp. 637-681, Springer, New York.

Jiang, F., S. Speziale, and T. S. Duffy (2006), Single-crystal elasticity of brucite, $\mathrm{Mg}(\mathrm{OH})_{2}$, to $15 \mathrm{GPa}$ by Brillouin scattering, Am. Mineral., 91, 1893-1900.

Kimura, J., Y. Yamagishi, and K. Kurita (2007), Tectonic history of Europa: Coupling between internal evolution and surface stresses, Earth Planets Space, 59, 113-125.

Kimura, J., T. Nakagawa, and K. Kurita (2009), Size and compositional constraints of Ganymede's metallic core for driving an active dynamo, Icarus, 202, 216-224.

Kirk, R. L., and D. J. Stevenson (1987), Thermal evolution of a differentiated Ganymede and implications for surface features, Icarus, 69, 91-134.

Langhans, M. H., et al. (2012), Titan's fluvial valleys: Morphology, distribution, and spectral properties, Planet. Spa. Sci., 60, 34-51. Le Corre, L., et al. (2009), Analysis of a cryolava flow-like feature on Titan, Planet. Space Sci., 57, 870-879.

Lebreton, J.-P., A. Coustenis, J. I. Lunine, F. Raulin, T. Owen, and D. Strobel (2009), Results from the Huygens probe on Titan, Astron. Astrophys. Rev., 17, 149-179. 
Leliwa-Kopystyński, J., M. Maruyama, and T. Nakajima (2002), The water-ammonia phase diagram up to 300 MPa: Application to icy satellites, Icarus, 159, 518-528.

Litwin, K. L., B. R. Zygielbaum, P. J. Polito, L. S. Sklar, and G. C. Collins (2012), Influence of temperature, composition, and grain size on the tensile failure of water ice: Implications for erosion on Titan, J. Geophys. Res., 117, E08013, doi:10.1029/2012JE004101.

Lopes, R. M. C., et al. (2007), Cryovolcanic features on Titan's surface as revealed by the Cassini Titan RADAR Mapper, Icarus, 186, 395-412. Lopes, R. M. C., et al. (2010), Distribution and interplay of geologic processes on Titan from Cassini RADAR data, Icarus, 205, 540-558.

Lopes, R. M. C., et al. (2013), Cryovolcanism on Titan: New results from Cassini RADAR and VIMS, J. Geophys. Res. Planets, 118, 416-435, doi:10.1002/jgre.20062.

Lorenz, R. D., et al. (2013), A global topographic map of Titan, Icarus, 225, 367-377.

Lunine, J. I., et al. (2008), Titan's diverse landscapes as evidenced by Cassini RADAR's third and fourth looks at Titan, Icarus, 195, 415-433. McKay, C. P., J. B. Pollach, and R. Courtin (1989), The thermal structure of Titan's atmosphere, Icarus, 89, 23-53.

Mitri, G., M. T. Bland, A. P. Showman, J. Radebaugh, B. Stiles, R. M. C. Lopes, I. J. Lunine, and R. T. Pappalardo (2010), Mountains on Titan: Modeling and observations, 115, E10002, doi:10.1029/2010JE003592.

Mitri, G., R. Meriggiola, A. Hayes, A. Lefevre, G. Tobie, A. Genova, J. I. Lunine, and H. Zebker (2014), Shape, topography, gravity anomalies and tidal deformation of Titan, Icarus, in press.

Mookherjee, M., and G. C. Capitani (2011), Trench parallel anisotropy and large delay time: Elasticity and anisotropy of antigorite at high pressures, Geophys. Res. Lett., 38, L09315, doi:10.1029/2011GL047160.

Mookherjee, M., and L. Stixrude (2009), Structure and elasticity of serpentine at high-pressure, Earth Planet. Sci. Lett., $279,11-19$.

Moore, J. M., and A. D. Howard (2010), Are the basins of Titan's Hotei Regio and Tui Regio sites of former low latitude seas?, Geophys. Res. Lett., 37, L22205, doi:10.1029/2010GL045234.

Moore, J. M., and R. T. Pappalardo (2011), Titan: An exogenic world?, Icarus, 212, 790-806.

Moore, W. B., and G. Schubert (2000), The tidal response of Europa, Icarus, 147, 317-319.

Murnaghan, F. D. (1967), Finite Deformation of an Elastic Solid, Dover Publications, Mineola, New York.

Nelson, R. M., et al. (2009), Saturn's Titan: Surface change, ammonia, and implications for atmospheric and tectonic activity, Icarus, 199, $429-441$.

Nimmo, F., and B. G. Bills (2010), Shell thickness variations and the long-wavelength topography of Titan, Icarus, 208, 896-904.

Nimmo, F., J. R. Spencer, R. T. Pappalardo, and M. E. Mullen (2007), Shear heating as the origin of the plumes and heat flux of Enceladus, Nature, 447, 289-291.

O'Rourke, J. G., and D. J. Stevenson (2014), Stability of ice/rock mixtures with application to a partially differentiated Titan, Icarus, 227, 67-77.

Peale, S. J. (1969), Generalized Cassini's law, Astronom. J., 74, 483-489.

Peale, S. J. (1977), Rotation histories of the natural satellites, in Planetary Satellites, edited by J. A. Burns, pp. 87-112, University of Arizona Press, Tucson.

Perrillat, J.-P., I. Daniel, K. T. Koga, B. Reynard, H. Cardon, and W. A. Crichton (2005), Kinetics of antigorite dehydration: A real-time X-ray diffraction study, Earth Planet. Sci. Lett., 236, 899-913.

Poirier, J. P., C. Sotin, and J. Peyronneau (1981), Viscosity of high-pressure ice VI and evolution and dynamics of Ganymede, Nature, 292, $225-227$.

Porco, C. C., et al. (2005), Imaging of Titan from the Cassini spacecraft, Nature, 434, 159-168.

Radebaugh, J., R. D. Lorenz, R. L. Kirk, J. I. Lunine, E. R. Stofan, R. M. C. Lopes, S. D. Wall, and the Cassini RADAR Team (2007), Mountains on Titan observed by Cassini RADAR, Icarus, 192, 77-91.

Radebaugh, J., et al. (2008), Dunes on Titan observed by Cassini RADAR, Icarus, 194, 690-703.

Radebaugh, J., et al. (2011), Regional geomorphology and history of Titan's Xanadu province, Icarus, 211, 672-685.

Sasaki, S., and K. Nakazawa (1986), Metal-silicate fractionation in the growing Earth: Energy source for the terrestrial magma ocean, $J$. Geophys. Res., 91, 9231-9238.

Schulze-Makuch, D., and L. N. Irwin (2008), Life in the Universe: Expectations and Constraints, Springer, NewYork.

Segatz, M., T. Spohn, M. N. Ross, and G. Schubert (1988), Tidal dissipation, surface heat flow, and figures of viscoelastic models of lo, Icarus, 75, 187-206.

Senshu, H., K. Kuramoto, and T. Matsui (2002), Thermal evolution of a growing Mars, J. Geophys. Res., 107(E12), 5118-5131, doi:10.1029/2001JE001819.

Shoji, D., H. Hussmann, K. Kurita, and F. Sohl (2013), Ice rheology and tidal heating of Enceladus, Icarus, 226, 10-19.

Smith-Konter, B., and R. T. Pappalardo (2008), Tidally driven stress accumulation and shear failure of Enceladus's tiger stripes, Icarus, 198, $435-451$.

Soderblom, L. A., et al. (2007), Correlations between Cassini VIMS spectra and RADAR SAR images: Implications for Titan's surface composition and the character of the Huygens probe landing site, Planet. Spa. Sci., 55, 2025-2036.

Soderblom, L. A., et al. (2009), The geology of Hotei Regio, Titan: Correlation of Cassini VIMS and RADAR, Icarus, 204, 610-618.

Sohl, F., H. Hussmann, B. Schwentker, T. Spohn, and R. D. Lorenz (2003), Interior structure models and tidal Love numbers of Titan, J. Geophys. Res., 108, 5130-5143, doi:10.1029/2003JE002044.

Sohl, F., F. W. Wagner, H. Hussmann, and M. Grott (2009), Planetary interiors, in Solar System; Landolt-Börnstein: Numerical Data and Functional Relationships in Science and Technology-New Series VI/4B, Astronomy, Astrophysics, and Cosmology, edited by J. E. Trümper, pp. 253-281, Springer, Berlin, Heidelberg, New York.

Sohl, F., M. Choukroun, J. Kargel, J. Kimura, R. Pappalardo, S. Vance, and M. Zolotov (2010), Subsurface water oceans on icy satellites: Chemical composition and exchange processes, Space Sci. Rev., 153, 485-510.

Solomonidou, A., G. Bampasidis, M. Hirtzig, A. Coustenis, K. Kyriakopoulos, K. S. Seymour, E. Bratsolis, and X. Moussas (2013), Morphotectonic features on Titan and their possible origin, Planet. Spa. Sci., 77, 104-117.

Sotin, C., et al. (2005), Release of volatiles from a possible cryovolcano from near-infrared imaging of Titan, Nature, 435, 786-789.

Sotin, C., et al. (2007), Cassini/VIMS observations of Titan during the T20 flyby, in 38th Lunar and Planetary Science Conference, (Lunar and Planetary Science XXXVIII), Held March 12-16, 2007 in League City, Texas. LPI Contribution No. 1338, pp. 2444.

Spohn, T., and G. Schubert (2003), Oceans in the icy satellites of Jupiter?, Icarus, 161, 456-467.

Stiles, B. W., et al. (2008), Determining Titan's spin state from Cassini RADAR images, Astrophys. J., 135, 1669-1680.

Stiles, B. W., et al. (2010), Erratum: Determining Titan's spin state from Cassini RADAR images, Astrophys. J., 139,311

Stixrude, L., and C. Lithgow-Bertelloni (2011), Thermodynamics of mantle minerals-II. Phase equilibria, Geophys. J. Int., 184, 1180-1213.

Stofan, E. R., et al. (2007), The lakes of Titan, Nature, 445, 61-64. 
Tachinami, C., H. Senshu, and S. Ida (2011), Thermal evolution and lifetime of intrinsic magnetic fields of super-Earths in habitable zones, Astrophys. J., 726, 70-88.

Tobie, G., O. Grasset, J. I. Lunine, A. Mocquet, and C. Sotin (2005), Titan's internal structure inferred from a coupled thermal-orbital model, Icarus, 175, 496-502.

Tobie, G., J. I. Lunine, and C. Sotin (2006), Episodic outgassing as the origin of atmospheric methane on Titan, Nature, 440, 61-64.

Tobie, G., D. Gautier, and F. Hersant (2012), Titan's bulk composition constrained by Cassini-Huygens: Implications for internal outgassing, Astrophys. J., 752, 125-145.

Tomasko, M. G., et al. (2005), Rain, winds and haze during the Huygens probe's descent to Titan's surface, Nature, 438, $765-778$.

Turcotte, D. L., and G. Schubert (2002), Geodynamics, Cambridge Univ. Press, New York.

Turtle, E. P., et al. (2011), Rapid and extensive surface changes near Titan's equator: Evidence of April showers, Science, 1331, $1414-1417$.

Wagner, F. W., F. Sohl, H. Hussmann, M. Grott, and H. Rauer (2011), Interior structure models of solid exoplanets using material laws in the infinite pressure limit, Icarus, 214, 366-376.

Wagner, F. W., N. Tosi, F. Sohl, H. Rauer, and T. Spohn (2012), Rocky super-Earth interiors: Structure and internal dynamics of CoRoT-7b and Kepler-10b, Astron. Astrophys., 541, A103-A116.

Wahr, J., Z. A. Selvans, M. E. Mullen, A. C. Barr, G. C. Collins, M. M. Selvans, and R. T. Pappalardo (2009), Modeling stresses on satellites due to nonsynchronous rotation and orbital eccentricity using gravitational potential theory, Icarus, 200, 188-206.

Wall, S. D., et al. (2009), Cassini RADAR images at Hotei Arcus and western Xanadu, Titan: Evidence for recent cryovolcanic activity, Geophys. Res. Lett., 36, L04203, doi:10.1029/2008GL036415.

Williams, D. A., J. Radebaugh, R. M. C. Lopes, and E. Stofan (2011), Geomorphologic mapping of the Menrva region of Titan using Cassini RADAR data, Icarus, 212, 744-750.

Wood, C. A., R. Lorenz, R. Kirk, R. Lopes, K. Mitchell, E. Stofan, and the Cassini RADAR Team (2010), Impact craters on Titan, Icarus, 206, 334-344.

Xia, X., D. J. Weidner, and H. Zhao (1998), Equation of state of brucite: Single-crystal Brillouin spectroscopy study and polycristalline pressure-volume-temperature measurement, Am. Mineral., 83, 68-74.

Zebker, H. A., B. Stiles, S. Hensley, R. Lorenz, R. L. Kirk, and J. Lunine (2009), Size and shape of Saturn's moon Titan, Science, 324, 921-923.

Zolotov, M. Y. (2007), An oceanic composition on early and today's Enceladus, Geophys. Res. Lett., 34, L23203, doi:10.1029/2007GL031234.

Zürn, W., and H. Wilhelm (1984), Tides of the solid Earth, in Geophysik der festen Erde, des Mondes und der Planeten; Landolt-Börnstein Neue Serie, V/2a, edited by K. Fuchs and H. Soffel, pp. 280-299, Springer, Berlin, Heidelberg, New York. 